TITLE:

\title{
Efficient Bayesian FFT method for damage detection using ambient vibration data with consideration of uncertainty
}

\author{
AUTHOR(S): \\ Zhang, Feng - Liang; Kim, Chul - Woo; Goi, \\ Yoshinao
}

\section{CITATION:}

Zhang, Feng - Liang ...[et al]. Efficient Bayesian FFT method for damage detection using ambient vibration data with consideration of uncertainty. Structural Control and Health Monitoring 2021, 28(2): e2659.

\section{ISSUE DATE:}

2021-02

URL:

http://hdl.handle.net/2433/267721

\section{RIGHT:}

This is the peer reviewed version of the following article: [Zhang, F-L, Kim, C-W, Goi, Y. Efficient Bayesian FFT method for damage detection using ambient vibration data with consideration of uncertainty. Struct Control Health Monit. 2021; 28:e2659.], which has been published in final form at https://doi.org/10.1002/stc.2659. This article may be used for noncommercial purposes in accordance with Wiley Terms and Conditions for Use of Self-Archived Versions. This article may not be enhanced, en riched or otherwise transformed into a derivative work, without express permission from Wiley or by statutory rights under applicable legislation. Copyright notices must not be removed, obscured or modified. The article must be linked to Wiley's version of record on Wiley Online Library and any embedding, framing or otherwise making available the article or pages thereof by third parties from 


\section{Efficient Bayesian FFT method for damage detection using ambient vibration data with consideration of uncertainty}

Feng-Liang Zhang ${ }^{1,2}$, Chul-Woo Kim²* and Yoshinao Goi ${ }^{2}$

${ }^{1}$ School of Civil and Environmental Engineering, Harbin Institute of Technology, Shenzhen 518055, China

${ }^{2}$ Department of Civil and Earth Resources Engineering, Kyoto University, Kyoto 615-8540, Japan

Abstract: Damage detection is one important target in structural health monitoring (SHM). Vibration-based damage detection has attracted more attention in the past decades by tracking the modal parameter changes of objective structures. This paper presents the work on developing a novel Bayesian Fast Fourier Transform (FFT) method for damage detection using the Bayes factor based on ambient vibration data. Based on the properties of FFT data, the likelihood function and prior probability density function (PDF) can be constructed theoretically based on a Gaussian distribution. The most probable value (MPV) of modal parameters and the associated covariance matrix determined from the ambient vibration data can be integrated into the model developed according to the Bayes factor. A novel damage indicator in the frequency domain is proposed, which can be calculated efficiently using the FFT data and the identified modal parameters. The method is illustrated using synthetic data where a simply supported bridge with 10 elements is simulated. It is found that the damage indicator can identify the damage element in both damage location and extent when moving the sensors installed on the bridge. The proposed method is also applied in a steel truss bridge and an ASCE benchmark structure. This method can make full use of the FFT data, modal parameters information and their posterior uncertainties, providing a new way for future damage detection.

Keywords: Bayes factor, damage indicator, Fast Bayesian FFT method, vibrationbased, modal parameters, posterior uncertainty

*Corresponding author, Professor, E-mail: kim.chulwoo.5u@kyoto-u.ac.jp 


\section{Introduction}

Structural health monitoring (SHM) has been attracting more attention in the past two decades with the increasing age of structures [1][2][3][4][5][6]. In the recent two years, the sudden collapse of some structures, such as Ponte Morandi in Italy in August 2018, which was the first cable-stayed concrete bridge in Europe, and the Miami pedestrian bridge in March, 2018, which is still under construction, has caused huge casualties and property losses. How to find the initial damages before the structural collapse is a very important issue in SHM. There are three main stages in damage detection. The first is to judge whether damage exists; the second is the damage location and the last is the damage extent. Focused on the three targets, many methods have been developed. Cha and Choi developed a method using convolutional neural networks to detect concrete cracks [7]. This method is a vision-based method and deep learning technology was used to analyze the image features and then the possible cracks. Eraky et al. proposed a damage indicator method by comparing the change of modal strain energies in different damage extents [8]. This method was verified in numerical examples and applied in experimental flexural structures. Ding et al. presented an improved Dempster-Shafer data fusion algorithm to perform damage assessment of structures considering the existing uncertainty based on Dempster-Shafer evidence theory [9]. In this method, the actual evidence reliabilities in damage assessment can be reflected well. The reliability evaluation method can also be used in the damage assessment of slopes $[10]$.

Modal curvatures can also be used for damage detection. Ciambella and Vestroni proposed a method to use modal curvatures for damage localization of beam-type structures [11]. The lower and higher modes effect was addressed to study the issue of narrow and broad damage. Another type of method for damage detection is the Bayesian method [12]. Yang and Lam developed a novel Bayesian model updating method to carry out damage detections [13]. Model updating can be performed effectively by adaptive sequential Monte Carlos. It was applied in a scaled transmission tower. Some other methods have also been developed such as the wavelet transform 
method [14][15], the artificial neural networks method [16][17][18], the lamb wave method [19][20], the piezoelectric-based smart aggregates active monitoring method [21] and the guided wave method [22][23], etc.

Among all the above methods, the vibration-based method is a commonly used one. Acceleration and velocity responses are easily collected and so they are frequently used in the damage detection. Based on these data, the modal properties including natural frequency, damping ratio and mode shape can be identified. By tracking the change of these parameters, it is possible to detect the potential damage. Among different vibration test methods, the ambient vibration test is more convenient to be used since no artificial excitation is required. However, since the excitations mainly come from the environment and they are random, it inevitably leads to the uncertainty existing in the identified modal parameters. How to quantify these uncertainties in vibration-based damage detection is an important issue. The Bayesian method makes it possible to evaluate the uncertainties of modal parameters under ambient excitations [24][25]. Recently, a fast Bayesian FFT method has been developed successfully for ambient modal identification and is becoming popular due to the fact that it is easily used and efficient [26][27][28][29][30][31][32][33]. It has been applied in the modal identification of different types of structures, for example, super tall buildings, long span bridges, and so on [34][35][36].

On the other hand, the Bayes factor was used to quantify the support for a model over another model [37][38][39][40][41]. Based on this property, it can be used in the comparison of the model in different damage statuses. Goi and Kim developed a time domain damage detection method based on the Bayes factor and it was applied well in the damage detection of a real bridge [42][43]. Compared with the time domain method, the frequency domain method has the advantage of easily taking into account the contributions of different efficient modes. Furthermore, some useless information that is difficult to model in the time domain can be removed conveniently in the frequency domain.

Therefore, combining the advantages of the Fast Bayesian FFT method and Bayes 
factor, in this work, a frequency domain method is proposed to provide a novel damage indicator for vibration-based damage detection based on ambient vibration data. The main advantage of the proposed method is that it can make full use of the information of natural frequencies, damping ratios and mode shapes instead of the traditional methods only using the natural frequencies or mode shapes. The associated posterior uncertainties of the identified modal parameters can also be addressed in the developed model. The proposed method is verified using a series of numerical examples by considering the change of damage location, damage extent and the information used. It is found that the developed damage indicator can reflect the damage change in this process. Finally, the proposed method is applied to a truss bridge and an ASCE Benchmark frame structure.

This paper is organized as follows. In Section 2, the theory of the proposed method is presented and a procedure for damage detection using this method is also introduced. Section 3 provides the numerical examples to illustrate the proposed method, followed by Section 4 to apply the proposed method in real structures. This work is concluded in Section 5 .

\section{Methodology}

In this section, the basic theory of the proposed method will be presented. The main contribution is highlighted briefly as follows. By substituting the likelihood function and the prior probability density functions (PDF) determined based on the theory of the recently developed fast Bayesian FFT method into the Bayes factor, a novel frequency domain damage indicator can be developed. The procedure to calculate the damage indicator is also proposed. In this part, a damage indicator is defined based on Bayes factor in section 2.1. In section 2.2, the likelihood function and the prior PDF to construct the damage indicator are developed. Based on the likelihood function and the prior PDF, the damage indicator is calculated and reformulated in section 2.3. Finally, the procedure to determine the damage indicator is proposed in section 2.4. 


\subsection{Definition of damage indicator}

The Bayes factor has been used in many studies [37]-[41]. Given data D, it is assumed that there are two hypotheses $\mathrm{H}_{1}$ and $\mathrm{H}_{0}$, whose PDF can be written as: $p\left(\mathrm{D} \mid \mathrm{H}_{1}\right)$ and $p\left(\mathrm{D} \mid \mathrm{H}_{0}\right)$, respectively. The definition of a Bayes factor can be given as follows [38]:

$$
\mathrm{B}_{10}=\frac{p\left(\mathrm{D} \mid \mathrm{H}_{1}\right)}{p\left(\mathrm{D} \mid \mathrm{H}_{0}\right)}
$$

The PDF of $p\left(\mathrm{D} \mid \mathrm{H}_{q}\right)(q=0,1)$ can be obtained by integrating as follows:

$$
p\left(\mathrm{D} \mid \mathrm{H}_{q}\right)=\int p\left(\mathrm{D} \mid \boldsymbol{\theta}_{q}, \mathrm{H}_{q}\right) p\left(\boldsymbol{\theta}_{q} \mid \mathrm{H}_{q}\right) d \boldsymbol{\theta}_{q}
$$

where $\boldsymbol{\theta}_{q}$ denotes a vector including all the parameters to construct the model under the hypothesis $\mathrm{H}_{q} ; p\left(\mathrm{D} \mid \boldsymbol{\theta}_{q}, \mathrm{H}_{q}\right)$ denotes the likelihood function of $\boldsymbol{\theta}_{q}$ under $\mathrm{H}_{q}$; $p\left(\boldsymbol{\theta}_{q} \mid \mathrm{H}_{q}\right)$ denotes the prior PDF of $\boldsymbol{\theta}_{q}$ given the hypothesis $\mathrm{H}_{q}$.

The integral of Equation (2) is usually intractable and so some numerical methods are needed to calculate it. In this work, Laplace's Method is used to solve this problem. In this method, assuming that the posterior PDF proportional to $p\left(\mathrm{D} \mid \boldsymbol{\theta}_{q}, \mathrm{H}_{q}\right) p\left(\boldsymbol{\theta}_{q} \mid \mathrm{H}_{q}\right)$ is highly peaked at its maximum value $\widetilde{\boldsymbol{\theta}}_{q}$, the integral in Equation (2) can be expressed as:

$$
p\left(\mathrm{D} \mid \mathrm{H}_{q}\right) \approx(2 \pi)^{n_{\theta} / 2}|\widetilde{\mathbf{C}}|^{1 / 2} p\left(\mathrm{D} \mid \widetilde{\boldsymbol{\theta}}_{q}, \mathrm{H}_{q}\right) p\left(\widetilde{\boldsymbol{\theta}}_{q} \mid \mathrm{H}_{q}\right)
$$

where $\widetilde{\boldsymbol{\theta}}_{q}$ is the mean value; $\tilde{\mathbf{C}}$ denotes the covariance matrix of the parameters in $\boldsymbol{\theta}_{q}$ with respect to $\tilde{L}=-\log \left[p\left(\mathrm{D} \mid \boldsymbol{\theta}_{q}, \mathrm{H}_{q}\right) p\left(\boldsymbol{\theta}_{q} \mid \mathrm{H}_{q}\right)\right]$ and the Hessian of $\tilde{L}$ is evaluated at $\widetilde{\boldsymbol{\theta}}_{q} ; n_{\theta}$ denotes the number of parameters inside $\boldsymbol{\theta}_{q}$. In this equation, $\tilde{\mathbf{C}}$ needs to be calculated as the inverse of the Hessian matrix by taking the second derivatives of $\tilde{L}$. Variants on Laplace's Method can be used to simplify the problem. A variant on this method is listed as follows:

$$
p\left(\mathrm{D} \mid \mathrm{H}_{q}\right) \approx(2 \pi)^{n_{\theta} / 2}\left|\widehat{\mathbf{C}}_{L}\right|^{1 / 2} p\left(\mathrm{D} \mid \widehat{\boldsymbol{\theta}}_{q}, \mathrm{H}_{q}\right) p\left(\widehat{\boldsymbol{\theta}}_{q} \mid \mathrm{H}_{q}\right)
$$

where $\widehat{\boldsymbol{\theta}}_{q}$ denotes the maximum likelihood estimator and it is the minimum point of 
$L=-\log \left[p\left(\mathrm{D} \mid \boldsymbol{\theta}_{q}, \mathrm{H}_{q}\right)\right] ; \hat{\mathbf{C}}_{L}$ denotes the covariance matrix with respect to $L$, which can be determined as the inverse of the Hessian matrix obtained by the second derivatives of the $L$; the Hessian of $L$ is evaluated at $\widehat{\boldsymbol{\theta}}_{q}$.

The Equation (3) is obtained at the maximum $\widetilde{\boldsymbol{\theta}}_{q}$ from approximation of the integral by means of the Laplace method (Laplace approximation). On the other hand, Equation (4) is an approximation of Equation (3) by omitting the prior PDF in the calculation of Hessian, and so Equation (4) is likely to be less accurate than Equation (3). The error between the two equations could be more when the prior PDF is more informative. In summary, Equation 4 is easier but less accurate than Equation 3, but the accuracy is still under control.

In this problem, based on the framework of Fast Bayesian FFT method, the prior PDF is not informative to the likelihood function. This is because the likelihood function is fast varying compared to the prior PDF when there is a large amount of data as the case in ambient vibration tests [27]. Therefore, Equation (4) will be used in this proposed method. In the next section, the likelihood function and the corresponding Hessian matrix are calculated based on the framework of the Fast Bayesian FFT method.

\subsection{Construction of the likelihood function and prior information}

Based on Equations (1) and (4) in section 2.1, the general form of the Bayes factor to determine the damage indicator can be obtained. Note that in Equation (4), there are three terms to be determined, i.e., the likelihood function $p\left(\mathrm{D} \mid \widehat{\boldsymbol{\theta}}_{q}, \mathrm{H}_{q}\right)$, the covariance matrix $\widehat{\mathbf{C}}_{L}$ and the prior PDF $p\left(\widehat{\boldsymbol{\theta}}_{q} \mid \mathrm{H}_{q}\right)$. In this section, these terms will be determined based on the framework of the fast Bayesian FFT approach [24][26][27]. Note that in the Bayesian framework, $\widehat{\boldsymbol{\theta}}_{q}$ denotes the most probable values (MPVs) of modal parameters.

Let $\left\{\widehat{\hat{\mathbf{x}}}_{j} \in R^{n}: j=1, \ldots, N\right\}$ denote the measured acceleration data under ambient conditions at $n$ degrees of freedom (DOFs) of a structure, abbreviated as $\left\{\hat{\mathbf{x}}_{j}\right\} ; N$ is the 
number of samples. It can be modelled as follows:

$$
\widehat{\mathbf{x}}_{j}=\ddot{\mathbf{x}}_{j}+\mathbf{e}_{j}
$$

where $\ddot{\mathbf{x}}_{j} \in R^{n}$ denotes the model acceleration response; $\mathbf{e}_{j} \in R^{n}$ denotes the prediction error to model the difference between the measured and theoretical structural responses.

The FFT of measured data $\left\{\widehat{\mathbf{x}}_{j}\right\}$ is defined as follows:

$$
\widehat{F}_{k}=\sqrt{\frac{2 \Delta t}{N}} \sum_{j=1}^{N} \widehat{\hat{\mathbf{x}}}_{j} \exp \left[-2 \pi \mathbf{i} \frac{(j-\mathbf{1})(k-\mathbf{1})}{N}\right] \quad(k=1,2, \ldots N)
$$

where $k$ is the index of the frequency $\mathrm{f}_{k}=(k-1) / N \Delta t$ corresponding to FFT $\hat{F}_{k}$ at $f_{k}$, and $k=2,3, \ldots N_{q}$ with $N_{q}=\operatorname{int}[N / 2]+1 ; \Delta t$ represents the sampling interval; $\mathbf{i}^{2}=-1$.

In the frequency domain, specified frequency bands will cover the possible modes. Given the $i$ th selected frequency band, let $D_{i}$ denote the FFT data containing the potential modes. According to Bayes' Theorem, the posterior PDF of $\overline{\boldsymbol{\theta}}_{i}$ for given data, where $\overline{\boldsymbol{\theta}}_{i}$ denotes the modal parameters in the $i$ th selected frequency band, can be expressed as:

$$
p\left(\overline{\boldsymbol{\theta}}_{i} \mid D_{i}\right)=\frac{p\left(\overline{\boldsymbol{\theta}}_{i}\right) p\left(D_{i} \mid \overline{\boldsymbol{\theta}}_{i}\right)}{p\left(D_{i}\right)}
$$

where $p\left(D_{i} \mid \overline{\boldsymbol{\theta}}_{i}\right)$ is the likelihood function; $p\left(D_{i}\right)$ is a constant; $p\left(\overline{\boldsymbol{\theta}}_{i}\right)$ is the prior PDF; $i$ is the index of the frequency band selected for modal identification.

The likelihood function $p\left(D_{i} \mid \overline{\boldsymbol{\theta}}_{i}\right)$ can be obtained as follows. Let $\widehat{\mathbf{Z}}_{i k}=$ $\left[\operatorname{Re} \widehat{F}_{i k} ; \operatorname{Im} \widehat{F}_{i k}\right] \in R^{2 n}$ where $\operatorname{Re} \widehat{F}_{i k}$ and $\operatorname{Im} \widehat{F}_{i k}$ denote the real and imaginary parts of the FFT data in the $i$ th selected frequency band at frequency $\mathrm{f}_{k}$, respectively; let $D_{i}=$ $\left\{\widehat{\mathbf{Z}}_{i k}\right\}$. The likelihood function $p\left(D_{i} \mid \overline{\boldsymbol{\theta}}_{i}\right)$ in the $i$ th frequency band can be constructed by a Gaussian distribution since the vector $\widehat{\mathbf{Z}}_{i k}$ is independent and follows a Gaussian distribution if having enough data, i.e.,

$$
p\left(D_{i} \mid \overline{\boldsymbol{\theta}}_{i}\right)=\prod_{\boldsymbol{k}} \frac{1}{(2 \pi)^{n} \operatorname{det}\left(\mathbf{C}_{i k}\right)^{\mathbf{0} .5}} \exp \left[-\frac{1}{2} \widehat{\mathbf{Z}}_{i k}^{\mathrm{T}} \mathbf{C}_{i k}^{-1} \widehat{\mathbf{Z}}_{i k}\right]
$$


in which, $\mathbf{C}_{\boldsymbol{i} \boldsymbol{k}}$, the covariance matrix of $\widehat{\mathbf{Z}}_{i k}$, is expressed as:

$$
\mathbf{C}_{i k}=\frac{1}{2}\left[\begin{array}{ll}
\boldsymbol{\Phi}_{i} & \\
& \boldsymbol{\Phi}_{i}
\end{array}\right]\left[\begin{array}{cc}
\operatorname{Re}_{i k} & -\operatorname{Im} \mathbf{H}_{i k} \\
\operatorname{Im}_{i k} & \operatorname{ReH}_{i k}
\end{array}\right]\left[\begin{array}{cc}
\boldsymbol{\Phi}_{i}^{T} & \\
& \boldsymbol{\Phi}_{i}^{T}
\end{array}\right]+\frac{s_{e_{i}}}{2} \mathbf{I}_{2 n}
$$

where $\boldsymbol{\Phi}_{\boldsymbol{i}}=\left[\boldsymbol{\Phi}_{i 1}, \boldsymbol{\Phi}_{i 2}, \ldots, \boldsymbol{\Phi}_{i m_{i}}\right] \in R^{n m_{i}}$ denotes the mode shape matrix; $\mathbf{I}_{2 n}$ is an $2 n \times 2 n$ identify matrix; $S_{e_{i}} \in R$ is the PSD of prediction error in the $i$ th frequency band; $\mathbf{H}_{i k}$ is a transfer function, and:

$$
\mathbf{H}_{i k}(u, v)=S_{u v}\left[\left(1-\beta_{i u k}^{2}\right)+\mathbf{i}\left(2 \zeta_{i u} \beta_{i u k}\right)\right]^{-1}\left[\left(1-\beta_{i v k}^{2}\right)-\mathbf{i}\left(2 \zeta_{i v} \beta_{i v k}\right)\right]^{-1}(10)
$$

where $\beta_{i u k}=f_{i u} / \mathrm{f}_{k} ; S_{u v}$ denotes the cross spectral density between the $u$ th and $v$ th modal excitation. Define $\overline{\boldsymbol{\theta}}_{i}=\left\{f_{i u}, \zeta_{i u}, S_{i u}, \boldsymbol{\Phi}_{i u}: u=1, \ldots, m_{i}, S_{e_{i}}\right\}$, in which, $m_{i}$ is the number of modes in a frequency band; $f_{i u} \in R$ is the $u$ th natural frequency in the $i$ th frequency band; similarly, $\zeta_{i u} \in R, S_{i u} \in R$ and $\boldsymbol{\Phi}_{i u} \in R^{n}$ denote the damping ratio, PSD of modal force and mode shape, respectively.

\subsubsection{Likelihood function and the corresponding covariance matrix}

The corresponding negative log-likelihood function (NLLF) can be expressed as:

$$
L\left(\overline{\boldsymbol{\theta}}_{i}\right)=-\ln p\left(D_{i} \mid \overline{\boldsymbol{\theta}}_{i}\right)
$$

and so

$$
p\left(D_{i} \mid \overline{\boldsymbol{\theta}}_{i}\right)=\exp \left[-L\left(\overline{\boldsymbol{\theta}}_{i}\right)\right]
$$

Based on a second-order Taylor expansion, it can be given by:

$$
L\left(\overline{\boldsymbol{\theta}}_{i}\right) \sim L\left(\widehat{\boldsymbol{\theta}}_{i}\right)+\frac{1}{2}\left(\overline{\boldsymbol{\theta}}_{i}-\widehat{\boldsymbol{\theta}}_{i}\right)^{T} \widehat{\mathbf{H}}_{L}\left(\overline{\boldsymbol{\theta}}_{i}-\widehat{\overline{\boldsymbol{\theta}}}_{i}\right)
$$

where $\widehat{\mathbf{H}}_{L}$ denotes the Hessian matrix of $L\left(\overline{\boldsymbol{\theta}}_{i}\right)$ when given the MPV $\widehat{\overline{\boldsymbol{\theta}}}_{i}$. Substituting (13) into (12), the likelihood function can be given by:

$$
p\left(D_{i} \mid \overline{\boldsymbol{\theta}}_{i}\right) \sim \exp \left[-\frac{1}{2}\left(\overline{\boldsymbol{\theta}}_{i}-\widehat{\boldsymbol{\theta}}_{i}\right)^{T} \hat{\mathbf{C}}_{\boldsymbol{\theta}_{i}}^{-\mathbf{1}}\left(\overline{\boldsymbol{\theta}}_{i}-\widehat{\boldsymbol{\theta}}_{i}\right)\right]
$$

with 


$$
\widehat{\mathbf{C}}_{\overline{\boldsymbol{\theta}}_{i}}=\widehat{\mathbf{H}}_{L}^{-1}
$$

denoting the covariance matrix of the modal parameters.

The likelihood function in an individual frequency band can be determined according to Equation (8). In damage detection, usually all the possible identifiable modes will be used and the data in all the related frequency bands will be included. Assuming the data in $n_{b}$ frequency bands are available, the likelihood function considering all these frequency bands can be given by:

$$
p\left(\left\{D_{i}\right\} \mid\left\{\overline{\boldsymbol{\theta}}_{i}\right\}\right)=\prod_{i=\mathbf{1}}^{n_{\boldsymbol{b}}} p\left(D_{i} \mid \overline{\boldsymbol{\theta}}_{i}\right)=\prod_{i=\mathbf{1}}^{\boldsymbol{n}_{\boldsymbol{b}}} \prod_{k=k_{i 1}}^{k_{i 2}} \frac{\mathbf{1}}{(\mathbf{2 \pi})^{\boldsymbol{n}} \operatorname{det}\left(\mathbf{C}_{\boldsymbol{i k}}\right)^{\mathbf{0 . 5}}} \exp \left[-\frac{\mathbf{1}}{\mathbf{2}} \hat{\mathbf{Z}}_{i k}^{T} \mathbf{C}_{i k}^{-\mathbf{1}} \widehat{\mathbf{Z}}_{i k}\right](16)
$$

where $\left\{D_{i}: i=1, \ldots, n_{b}\right\}$ is a collection of the data in all the frequency bands, abbreviated as $\left\{D_{i}\right\} ;\left\{\overline{\boldsymbol{\theta}}_{i}: i=1, \ldots, n_{b}\right\}$ denotes a collection of the modal parameters in all the selected frequency bands, abbreviated as $\left\{\overline{\boldsymbol{\theta}}_{i}\right\} ; k_{i 1}$ and $k_{i 2}$ denote the start and end frequency indexes in the $i$ th selected frequency band, respectively.

\subsubsection{Prior PDF}

The prior PDF of $\boldsymbol{\theta}_{i}$ can be constructed as follows. The identified modal parameters can be modelled as:

$$
\widehat{\boldsymbol{\theta}}_{i}=\overline{\boldsymbol{\theta}}_{i}+\boldsymbol{\varepsilon}_{\boldsymbol{i}}
$$

where $\overline{\boldsymbol{\theta}}_{i}$ is the theoretical modal parameters and $\boldsymbol{\varepsilon}_{\boldsymbol{i}}$ is the prediction error of modal parameters between the identified and theoretical values. Assuming $\boldsymbol{\varepsilon}_{\boldsymbol{i}}$ follows a Gaussian distribution, then the prior PDF of $\overline{\boldsymbol{\theta}}_{i}$ can be given by:

$$
p\left(\overline{\boldsymbol{\theta}}_{i}\right)=\frac{\mathbf{1}}{(\mathbf{2 \pi})^{n} \operatorname{det}\left(\mathbf{C}_{\overline{\boldsymbol{\theta}}_{i}}\right)^{\mathbf{0 . 5}}} \exp \left[-\frac{\mathbf{1}}{\mathbf{2}}\left(\overline{\boldsymbol{\theta}}_{i}-\widehat{\overline{\boldsymbol{\theta}}}_{i}\right)^{T} \mathbf{C}_{\overline{\boldsymbol{\theta}}_{i}}^{-\mathbf{1}}\left(\overline{\boldsymbol{\theta}}_{i}-\widehat{\overline{\boldsymbol{\theta}}}_{i}\right)\right]
$$

where $\mathbf{C}_{\overline{\boldsymbol{\theta}}_{i}}$ denotes the covariance matrix of the modal parameters $\overline{\boldsymbol{\theta}}_{i}$ in the $i$ th frequency band. Since the modal parameters in different frequency bands can be taken to be independent, the prior PDF considering all these frequency bands can be given by:

$$
p\left(\left\{\overline{\boldsymbol{\theta}}_{i}\right\}\right)=\prod_{i=1}^{n_{b}} p\left(\overline{\boldsymbol{\theta}}_{i}\right)=\prod_{i=1}^{n_{b}} \frac{\mathbf{1}}{(\mathbf{2 \pi})^{n} \operatorname{det}\left(\mathbf{C}_{\overline{\boldsymbol{\theta}}_{i}}\right)^{\mathbf{0} .5}} \exp \left[-\frac{\mathbf{1}}{\mathbf{2}}\left(\overline{\boldsymbol{\theta}}_{i}-\widehat{\overline{\boldsymbol{\theta}}}_{i}\right)^{T} \mathbf{C}_{\boldsymbol{\theta}_{i}}^{-\mathbf{1}}\left(\overline{\boldsymbol{\theta}}_{i}-\widehat{\widehat{\boldsymbol{\theta}}}_{i}\right)\right]
$$




\subsection{Calculation of a new Bayesian damage indicator}

Based on the above sections, the new Bayesian damage indicator can be calculated as follows. Let $\mathrm{H}_{1}$ and $\mathrm{H}_{0}$ denote the alternative and null hypotheses, which can represent the damage and healthy statuses of the tested structure, respectively. Given the test data $\mathrm{D}$, where there may be damage information included, the Bayes factor can be given by:

$$
\mathrm{B}_{10}=\frac{p\left(\mathrm{D} \mid \mathrm{H}_{1}\right)}{p\left(\mathrm{D} \mid \mathrm{H}_{0}\right)}=\frac{\int p\left(\mathrm{D} \mid \boldsymbol{\theta}_{1}, \mathrm{H}_{1}\right) \mathrm{p}\left(\boldsymbol{\theta}_{1} \mid \mathrm{H}_{1}\right) d \boldsymbol{\theta}_{1}}{\int p\left(\mathrm{D} \mid \boldsymbol{\theta}_{0}, \mathrm{H}_{0}\right) \mathrm{p}\left(\boldsymbol{\theta}_{0} \mid \mathrm{H}_{0}\right) d \boldsymbol{\theta}_{0}}
$$

where $\boldsymbol{\theta}_{q}=\left\{\overline{\boldsymbol{\theta}}_{i}\right\}_{q}$ denotes a collection of all the modal parameters involved under the $q$ th hypothesis. Since both $\mathrm{p}\left(\mathrm{D} \mid \boldsymbol{\theta}_{q}, \mathrm{H}_{q}\right)$ and $\mathrm{p}\left(\boldsymbol{\theta}_{q} \mid \mathrm{H}_{q}\right)$ follow Gaussian distributions, $\mathrm{p}\left(\mathrm{D} \mid \boldsymbol{\theta}_{q}, \mathrm{H}_{q}\right) \mathrm{p}\left(\boldsymbol{\theta}_{q} \mid \mathrm{H}_{q}\right)$ is highly peaked. It is worth mentioning that $\mathrm{H}_{1}$ and $\mathrm{H}_{0}$ are two hypotheses. $\mathrm{H}_{1}$ represents the damage status while $\mathrm{H}_{0}$ represents the intact status. In the later calculation, $\mathrm{H}_{q}(q=1,0)$ will be ignored since the modal parameters in $\boldsymbol{\theta}_{q}(q=$ $1,0)$ are able to pin down the distribution of D already.

Note that the covariance matrix of the individual likelihood function can be given by Equation (15). Since the likelihood function in Equation (16) is a product of multivariate Gaussian PDFs, based on Equations (14) and (16), its covariance matrix under $\mathrm{H}_{q}$ hypothesis can be given by:

$$
\widehat{\mathbf{C}}_{L q}=\left(\sum_{i=1}^{n_{b}} \hat{\mathbf{C}}_{\overline{\mathbf{\theta}}_{i q}^{-1}}^{-1}\right)^{-1}
$$

where $\widehat{\mathbf{C}}_{\overline{\mathbf{\theta}}_{i q}}$ denotes the covariance matrix in the $i$ th frequency band under the $q$ th hypothesis.

Once the most probable values (MPVs) of the modal parameters are given, variants on Laplace's Method can be used to calculate the two integrals in Equation (20) according to Equation (4). Thus:

$$
\mathrm{B}_{10}=\frac{\left|\widehat{\boldsymbol{C}}_{L 1}\right|^{1 / 2} p\left(\mathrm{D} \mid \widehat{\boldsymbol{\theta}}_{1}, \mathrm{H}_{1}\right) p\left(\widehat{\boldsymbol{\theta}}_{1} \mid \mathrm{H}_{1}\right)}{\left|\widehat{\boldsymbol{C}}_{L 0}\right|^{1 / 2} p\left(\mathrm{D} \mid \widehat{\boldsymbol{\theta}}_{0}, \mathrm{H}_{0}\right) p\left(\widehat{\boldsymbol{\theta}}_{0} \mid \mathrm{H}_{0}\right)}
$$

where $\widehat{\boldsymbol{\theta}}_{q}=\left\{\widehat{\boldsymbol{\theta}}_{i}\right\}_{q}$. Note that the relative error is in the order of $\mathrm{O}\left(N^{-1}\right)$. In this study, ambient vibration data were used for the investigation. In order to ensure the 
identification accuracy, the number of data sample is usually very large. The stabilization of the results can be satisfied.

For the convenience of calculation, the natural logarithm of the Bayes factor is commonly used, i.e.,

$\ln \left(\mathrm{B}_{10}\right)=\frac{1}{2} \ln \left(\left|\widehat{\mathbf{C}}_{L 1}\right|\right)+\ln \left[p\left(\mathrm{D} \mid \widehat{\boldsymbol{\theta}}_{1}, \mathrm{H}_{1}\right)\right]+\ln \left[p\left(\widehat{\boldsymbol{\theta}}_{1} \mid \mathrm{H}_{1}\right)\right]-\frac{1}{2} \ln \left(\left|\widehat{\mathbf{C}}_{L 0}\right|\right)-\ln \left[p\left(\mathrm{D} \mid \widehat{\boldsymbol{\theta}}_{0}, \mathrm{H}_{0}\right)\right]-$

$\ln \left[p\left(\widehat{\boldsymbol{\theta}}_{0} \mid \mathrm{H}_{0}\right)\right]$

In this equation, $\widehat{\mathbf{C}}_{L 1}, p\left(\mathrm{D} \mid \widehat{\boldsymbol{\theta}}_{1}, \mathrm{H}_{1}\right)$ and $p\left(\widehat{\boldsymbol{\theta}}_{1} \mid \mathrm{H}_{1}\right)$ are calculated based on the modal parameters identified in the damage status, while $\widehat{\mathbf{C}}_{L 0}, p\left(\mathrm{D} \mid \widehat{\boldsymbol{\theta}}_{0}, \mathrm{H}_{0}\right)$ and $p\left(\widehat{\boldsymbol{\theta}}_{0} \mid \mathrm{H}_{0}\right)$ are calculated based on the modal parameters identified in the intact status.

\subsection{Procedure}

The basic procedure for calculating the new damage indicator can be concluded as follows:

1) Perform operational modal analysis of healthy and test data by the fast Bayesian FFT method, respectively. Determine the MPV of modal parameters, i.e., $\widehat{\boldsymbol{\theta}}_{q}(q=$ 1,0 ), and the associated covariance matrixes $\widehat{\mathbf{C}}_{\overline{\mathbf{\theta}}_{i q}}$ in all the selected frequency bands. Note that the modes identified in two sets of data should be consistent.

2) Given the test data, calculate the likelihood functions $p\left(\mathrm{D} \mid \widehat{\boldsymbol{\theta}}_{q}, \mathrm{H}_{q}\right)$ under $\mathrm{H}_{1}$ and $\mathrm{H}_{0}$ hypotheses respectively according to Equation (16) by substituting the modal parameters of two sets of data determined in Step 1.

3) Calculate $p\left(\widehat{\boldsymbol{\theta}}_{q} \mid \mathrm{H}_{q}\right)$ under $\mathrm{H}_{1}$ and $\mathrm{H}_{0}$ hypotheses respectively according to Equation (19).

4) Calculate $\widehat{\mathbf{C}}_{L q}$ according to Equation (21).

5) Calculate $\ln \left(\mathrm{B}_{10}\right)$ according to Equation (23).

\section{Numerical example}

To illustrate the proposed method, a simply supported bridge was simulated with the length of $21 \mathrm{~m}$. It was modelled by 10 beam elements as shown in Figure 1 and the first seven natural frequencies below $100 \mathrm{~Hz}$ were $1.609 \mathrm{~Hz}, 6.438 \mathrm{~Hz}, 14.493 \mathrm{~Hz}, 25.794$ $\mathrm{Hz}, 40.395 \mathrm{~Hz}, 58.400 \mathrm{~Hz}$ and $79.981 \mathrm{~Hz}$, respectively. The damping of all the modes was assumed to be classical and the damping ratios were set to be $1 \%$. Ambient 
excitations modelled by independently and identically distributed (i.i.d.) Gaussian white noise were applied to the bridge. The root PSD of the ambient excitation was $2 \mathrm{~N} / \sqrt{\mathrm{Hz}}$. Gaussian white noise with a root PSD of $6 \times 10^{-5} \mathrm{~g} / \sqrt{\mathrm{Hz}}$ was added into the generated data to simulate the measurement noise. Assume that all the nine DOFs in the vertical direction of the bridge were measured as shown in Figure 1 with a sampling frequency of $256 \mathrm{~Hz}$. For each measurement, $900 \mathrm{~s}$ of data were collected.

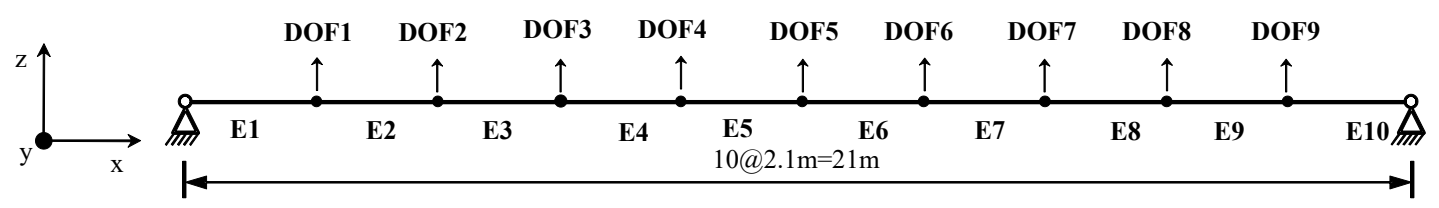

Figure 1 Overview of the bridge

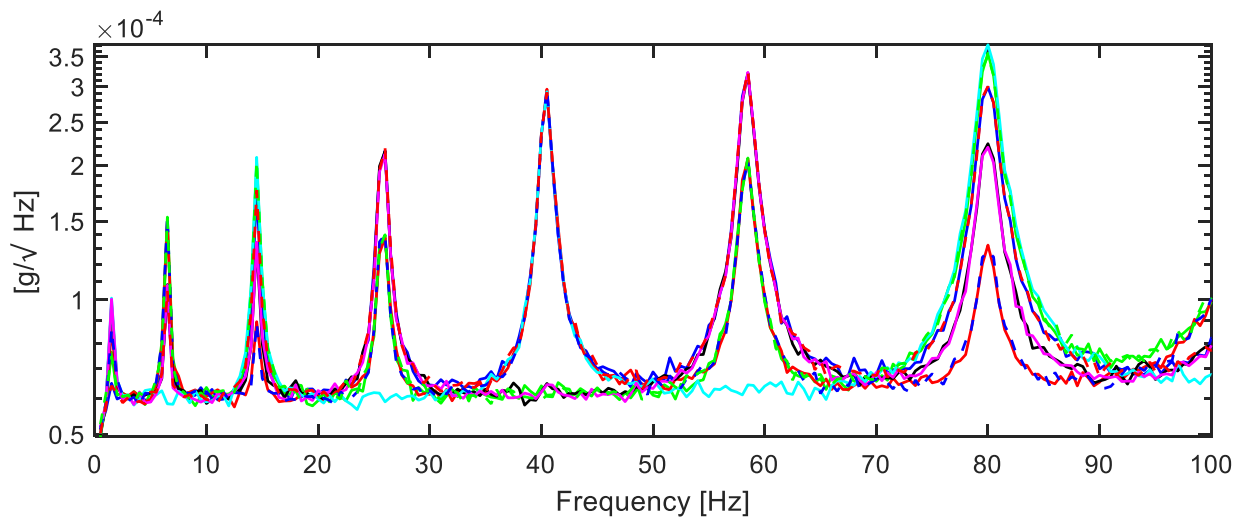

Figure 2 Root PSD spectral of the simulated data

Table 1 Modal parameters of the first seven modes

\begin{tabular}{|c|c|c|c|c|c|c|c|c|}
\hline \multicolumn{2}{|c|}{ Mode } & 1 & 2 & 3 & 4 & 5 & 6 & 7 \\
\hline \multirow{2}{*}{$\begin{array}{c}\text { Natural } \\
\text { frequency } \\
(\mathrm{Hz})\end{array}$} & Identified & 1.609 & 6.431 & 14.494 & 25.796 & 40.417 & 58.402 & 79.996 \\
\cline { 2 - 9 } & $\mathrm{COV}(\%)$ & 0.112 & 0.059 & 0.040 & 0.031 & 0.024 & 0.020 & 0.017 \\
\cline { 2 - 9 } & exact & 1.609 & 6.438 & 14.493 & 25.794 & 40.395 & 58.400 & 79.981 \\
\hline \multirow{2}{*}{$\begin{array}{c}\text { Damping } \\
\text { ratio }\end{array}$} & Identified (\%) & 0.86 & 0.93 & 0.99 & 1.04 & 1.00 & 0.97 & 1.01 \\
\cline { 2 - 9 } & $\mathrm{COV}(\%)$ & 14.1 & 6.7 & 4.5 & 3.3 & 2.6 & 2.2 & 1.9 \\
\cline { 2 - 9 } & Exact (\%) & 1.00 & 1.00 & 1.00 & 1.00 & 1.00 & 1.00 & 1.00 \\
\hline \multicolumn{2}{|c|}{ MAC } & 0.9996 & 0.9999 & 0.9999 & 1.0000 & 1.0000 & 1.0000 & 1.0000 \\
\hline
\end{tabular}

Figure 2 shows the PSD spectral of the simulated data. All these seven modes below $100 \mathrm{~Hz}$ were identified and used for the later damage detection. Table 1 shows the modal parameters identified using the Fast Bayesian FFT method. In addition to the MPV of modal parameters, the associated coefficient of variation (COV) was also calculated to evaluate the posterior uncertainty. The exact values of the modal parameters determined from the finite element model were also provided. The 
identified modal parameters were close to the exact values. The COVs of natural frequencies were small while the COVs of damping ratios were a little larger, indicating that the identification of natural frequency was more accurate.

The mode shapes were also identified as shown in Figure 3. It is seen that all these mode shapes are reasonable. The modal assurance criterion (MAC) between the identified and exact mode shapes are also listed in the last row of the table. It is seen that they are quite close to 1 , indicating that the identified mode shapes are almost the same as the corresponding exact ones.
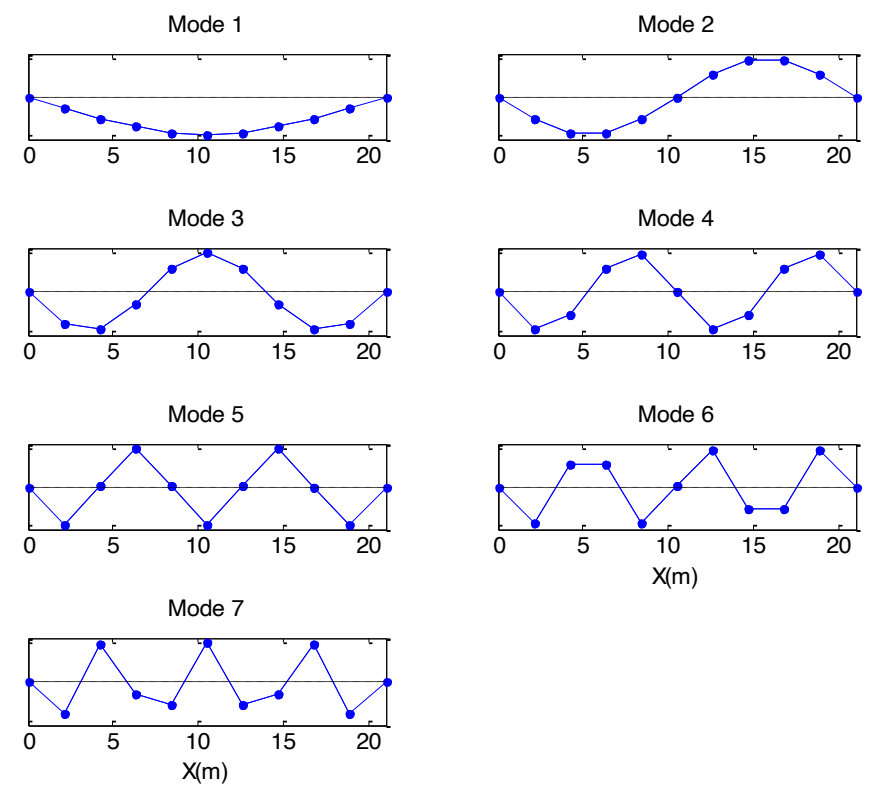

Figure 3 Mode shapes identified

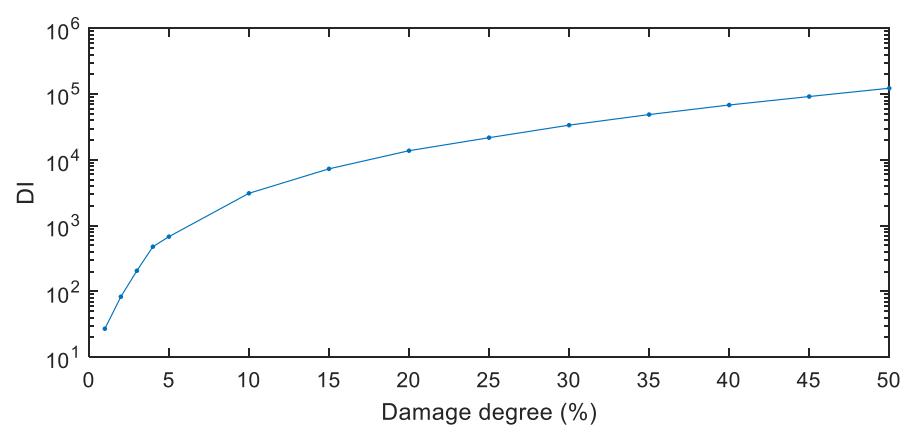

Figure 4 Damage degree with all the 9 DOFs measured, damage in Element 4, DI: damage indicator

\subsection{Damage appearing in one element}

To investigate the new damage indicator, the damage was simulated by reducing the elastic modulus of different corresponding elements. The damage degree is accounted 
for by the reduction rate as $1 \%, 2 \%, 3 \%, 4 \%, 5 \%, 10 \%, 15 \%, 20 \%, 25 \%, 30 \%, 35 \%$, $40 \%, 45 \%$ and $50 \%$. As mentioned, there were a total of 10 elements. To evaluate the damage behaviour in different locations, the damage was simulated for each element individually from the left to the right side, i.e., 10 different cases were investigated for each damage degree. In total, 140 sets of data were used for the illustration.

Figure 4 shows the relationship between bridge damage indicator (DI) and the damage degree when damage appears in Element 4, where all the nine DOFs were measured. The damage degree changes from $1 \%$ to $50 \%$. Following with the increase of damage degree, the DI increases accordingly. When the damage is very small, e.g., less than 5\%, the DI is also at a very low level, but their increasing with the damage degree can also be observed. This indicates that the DI is sensitive to the damage degree.

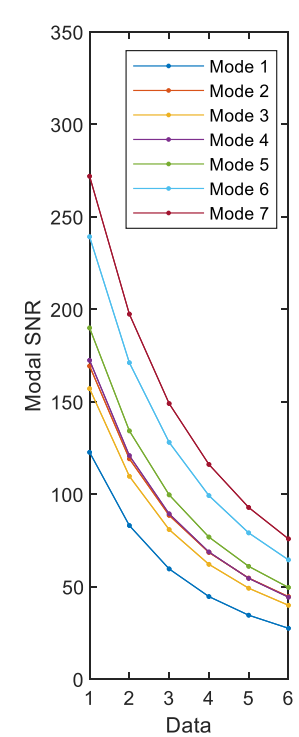

(a)

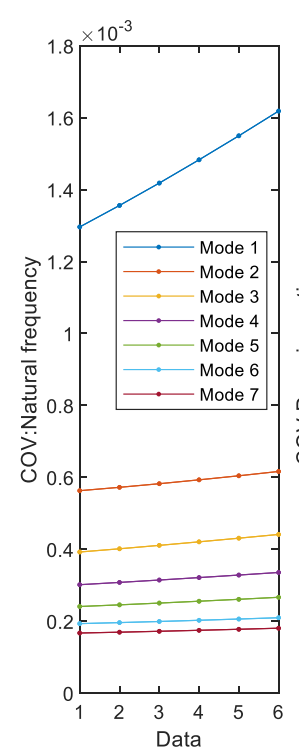

(b)

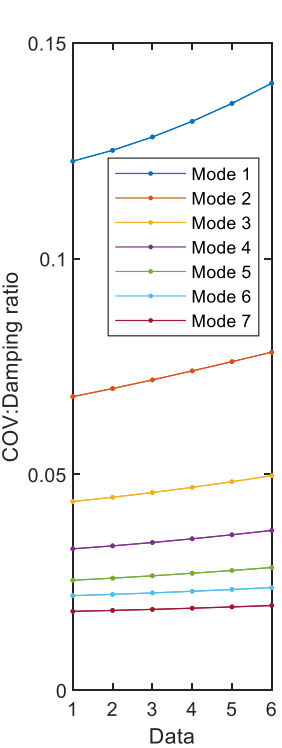

(c)

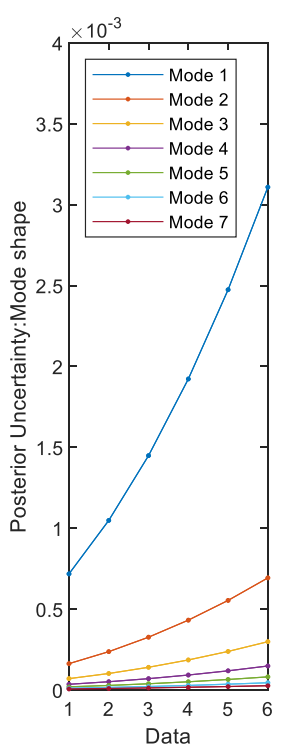

(d)

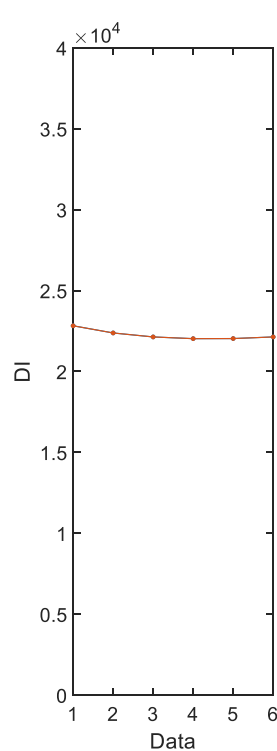

(e)

Figure 5 Noise levels effect of the damage indicator, damage in Element 4, damage degree of $25 \%$

Noise level is an important factor affecting the efficiency of the damage detection. To investigate this effect, six groups of data with six noise levels, i.e., the root PSD of 5 $\times 10^{-5} \mathrm{~g} / \sqrt{\mathrm{Hz}}, 6 \times 10^{-5} \mathrm{~g} / \sqrt{\mathrm{Hz}}($ nominal value $), 7 \times 10^{-5} \mathrm{~g} / \sqrt{\mathrm{Hz}}, 8 \times 10^{-5} \mathrm{~g} / \sqrt{\mathrm{Hz}}$, $9 \times 10^{-5} \mathrm{~g} / \sqrt{\mathrm{Hz}}$ and $10 \times 10^{-5} \mathrm{~g} / \sqrt{\mathrm{Hz}}$, respectively, were generated. Figure 5 shows the noise level effects of the damage indicator, with the damage element in the $4^{\text {th }}$ element and the damage degree of $25 \%$. For the six groups of data, the noise levels 
increased gradually. Figure 5a shows the modal signal to noise ratio (SNR) ([26][27][28][29][44]) from Data 1 to Data 6 of all the seven modes used for damage detection. It is seen that with the increase of noise level, the modal SNRs in all the modes decrease obviously, while the COV of natural frequencies (Figure 5b), COV of damping ratios (Figure 5c), and the posterior uncertainty of mode shape (Figure 5d) increase consistently. This means that the increase of noise level makes the identification tend to be inaccurate. Figure 5e shows the damage indicator values at different noise levels. Although the modal SNR decreases obviously, the DI values tend to be stable, indicating that the proposed method has anti-noise performance.

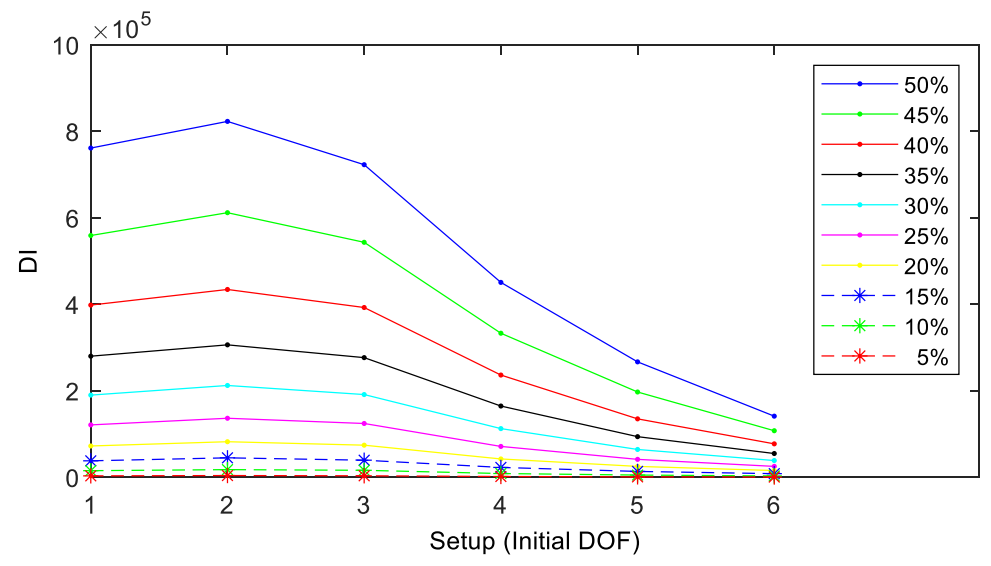

Figure 6 DI for different damage degrees and measured DOFs, $1^{\text {st }}$ element

Table 2 Measurement plan

\begin{tabular}{|c|c|c|c|c|}
\hline Setup & Sensor 1 & Sensor 2 & Sensor 3 & Sensor 4 \\
\hline 1 & DOF1 & DOF2 & DOF3 & DOF4 \\
\hline 2 & DOF2 & DOF3 & DOF4 & DOF5 \\
\hline 3 & DOF3 & DOF4 & DOF5 & DOF6 \\
\hline 4 & DOF4 & DOF5 & DOF6 & DOF7 \\
\hline 5 & DOF5 & DOF6 & DOF7 & DOF8 \\
\hline 6 & DOF6 & DOF7 & DOF8 & DOF9 \\
\hline
\end{tabular}

In practice, not all the DOFs can be measured in real applications. In the simulation, it was assumed that only four sensors were available and these sensors were used to carry out the damage detection of the bridge based on DI. The four sensors were arranged from the left to the right sides of the bridge. The measurement plan can be seen in Table 2. Figure 6 to Figure 15 show the relationship between the DI and setups for different damage degrees. In these figures, the damage element changes from the $1^{\text {st }}$ to the $10^{\text {th }}$ 
element for the purpose of observing its effect on the DI. In general, with the increase of damage degree, the DI increases for all the cases with different damage elements and different measured DOFs, which is consistent with the results presented in Figure 4.

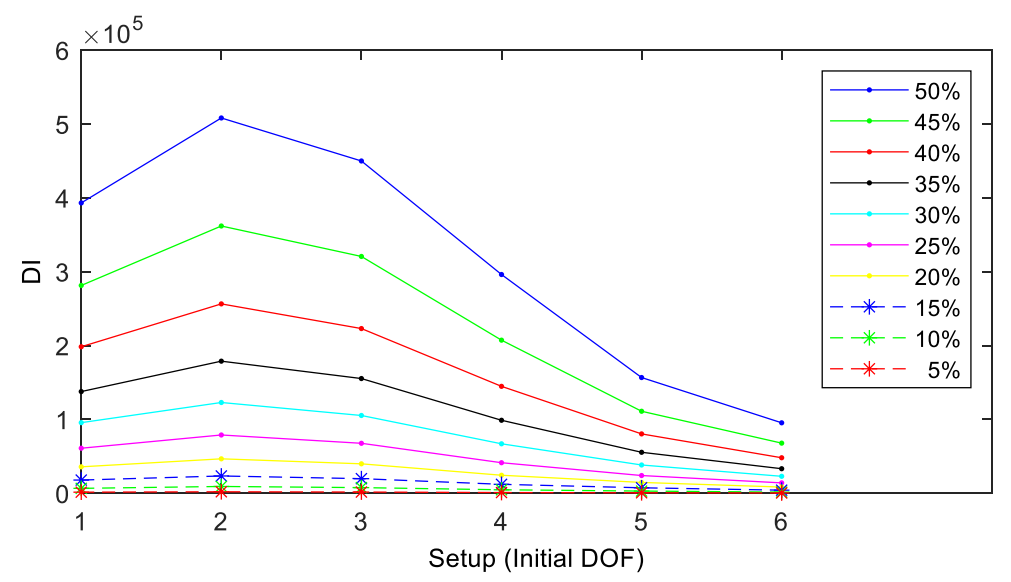

Figure 7 DI for different damage degrees and measured DOFs, damage in the $2^{\text {nd }}$ element

$\overline{0}$

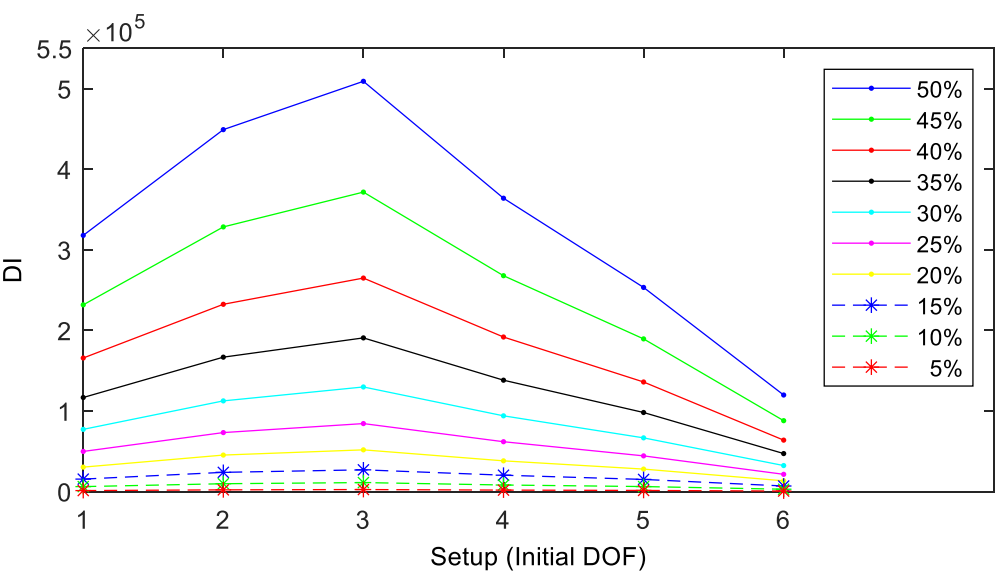

Figure 8 DI for different damage degrees and measured DOFs, damage in the $3^{\text {rd }}$ element

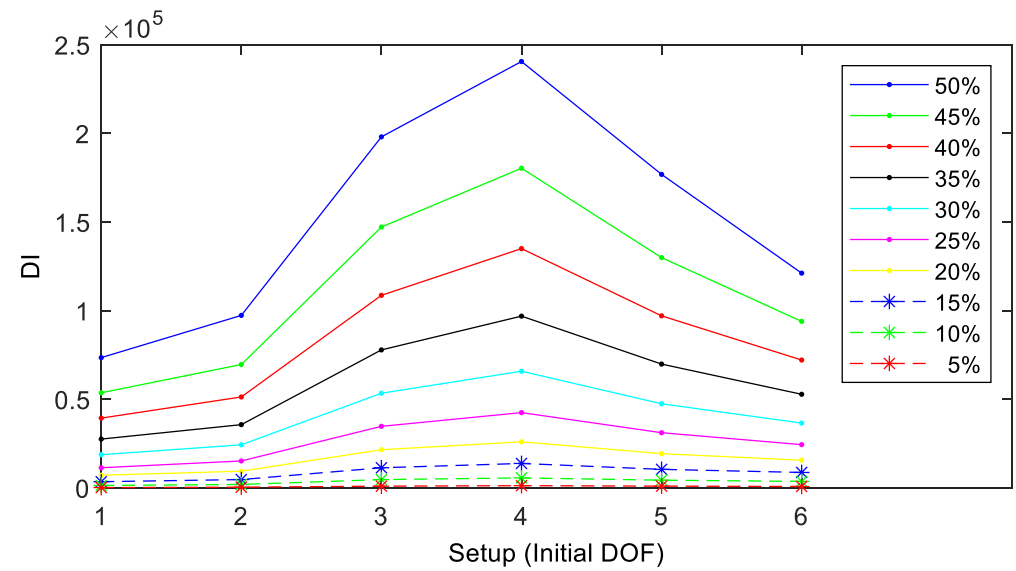

Figure 9 DI for different damage degrees and measured DOFs, damage in the $4^{\text {th }}$ element 
Figure 6 shows the DI for different damage degrees and measured DOFs, where the $1^{\text {st }}$ element is assumed to be damaged. According to Figure 1, the left side of the $1^{\text {st }}$ element is fixed while the right side corresponds to DOF1. From this figure, it is seen that in Setups 1 and 2, the DI values are all large and Setup 2 has the larger value. This means that the damage in the $1^{\text {st }}$ element significantly affects Setups 1 and 2. For the setups farther from the damage element, the DI value tends to decrease obviously.

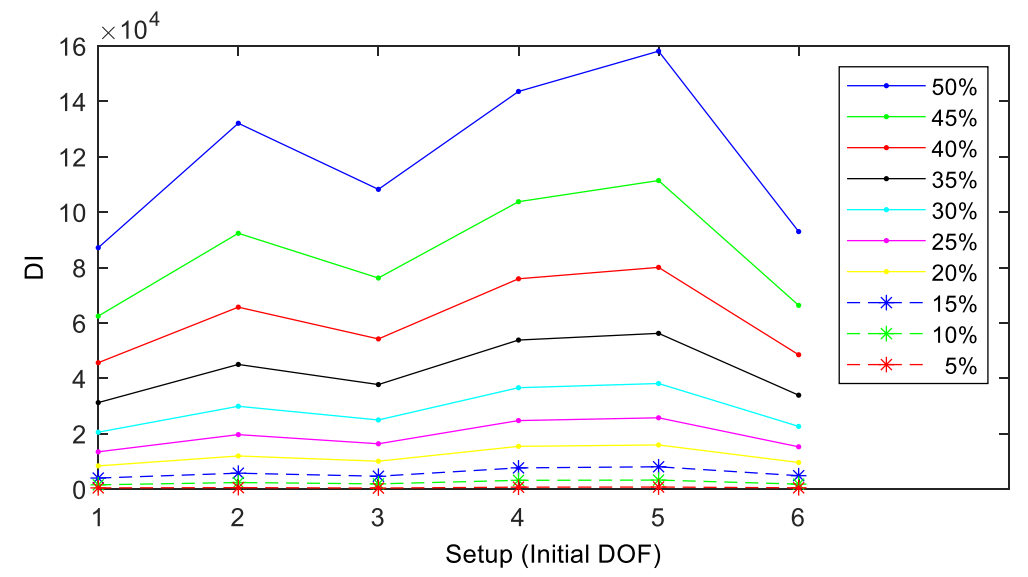

Figure 10 DI for different damage degrees and measured DOFs, damage in the $5^{\text {th }}$ element

Figure 7, Figure 8 and Figure 9 show the DI values for different damage degrees and measured DOFs, where the damage appears in the $2^{\text {nd }}$, the $3^{\text {rd }}$ and the $4^{\text {th }}$ element, respectively. It is seen that Setup 2 has the largest DI value when there is damage in the $2^{\text {nd }}$ element; Setup 3 and Setup 4 have the largest DI value when there is damage in the $3^{\text {rd }}$ and the $4^{\text {th }}$ element, respectively. This shows that when the sensors were put at one side of the damage, the corresponding DI value was the highest and this phenomenon was repeatable. One possible reason is that the damage element will more affect the mode shapes far away from the constraint.

It should be noted that there is some difference for the case in Figure 6, where the $1^{\text {st }}$ element is damaged but the DI value of Setup 1 is not the largest value. Instead, Setup 2 has the largest DI value. This may be because the left side of the $1^{\text {st }}$ element is fixed, and this boundary condition could affect the DI. Although the DI value of Setup 1 is the second largest, it is still significantly larger than the corresponding value of the case in Figure 7, where the $2^{\text {nd }}$ element is damaged. Furthermore, for the case in Figure 6 , the 
DI for Setup 1 is larger than the value for Setup 3; however, the reverse is true for the case in Figure 7, which shows that the behaviours when damage appearing in the $1^{\text {st }}$ and $2^{\text {nd }}$ elements are obviously different. This is because of the effect of the boundary condition on the DI. The damage appearing in the $1^{\text {st }}$ and $2^{\text {nd }}$ elements can still be detected using the indicator.

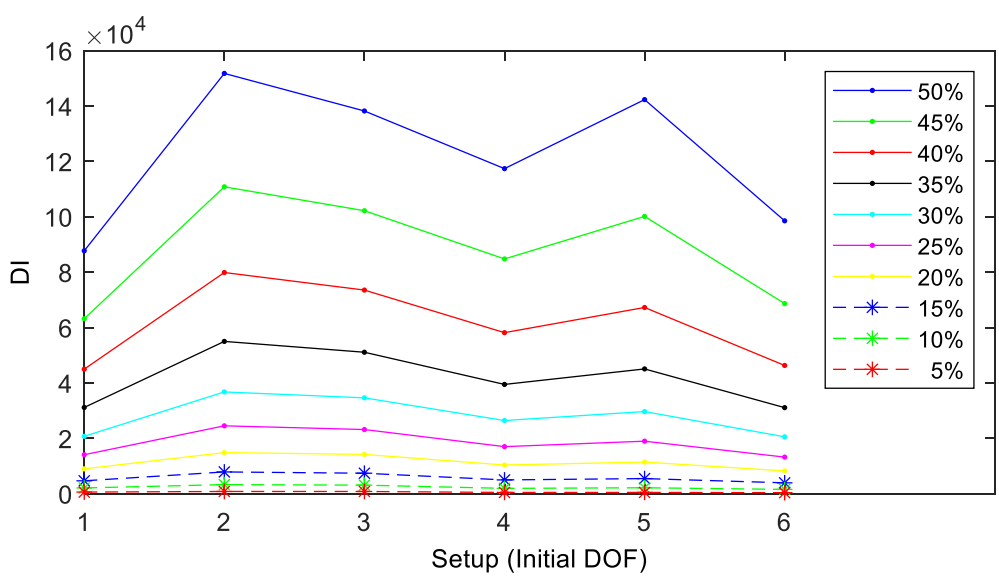

Figure 11 DI for different damage degrees and measured DOFs, damage in the $6^{\text {th }}$ element

Figure 10 shows the DI for different damage degrees and measured DOFs, where the damage appears in the $5^{\text {th }}$ element. In this case, as predicted, Setup 5 has the largest DI, indicating possible damage in the $5^{\text {th }}$ element. It is also interesting to find that in Setup 2 there is also a peak, which is smaller than the DI for Setup 5. This is because this damage element is almost in the middle of the bridge, which leads to Setup 5 having the first sensor beginning at Location 5 and Setup 1 with the last sensor ending at Location 4 perhaps having a larger DI. However, since the first location of Setup 1 is the first location of the bridge on the left side, as discussed, due to the effect of boundary conditions, the DI of this setup will be smaller. This conclusion is verified by the results in Figure 11 (the damage appearing in the $6^{\text {th }}$ element). It is seen that the DIs in Figure 10 and Figure 11 are symmetric, since the $5^{\text {th }}$ and $6^{\text {th }}$ elements are symmetric.

Similarly, the cases with damage appearing in the $7^{\text {th }}, 8^{\text {th }}, 9^{\text {th }}$ and $10^{\text {th }}$ element are symmetric with the cases when damage appearing in the $4^{\text {th }}, 3^{\text {rd }}, 2^{\text {nd }}$ and $1^{\text {st }}$ element, respectively. Therefore, the results in Figure 12, Figure 13, Figure 14 and Figure 15 look symmetric with the results in Figure 9, Figure 8, Figure 7 and Figure 6, respectively. 
The symmetric phenomenon also verifies the analysis before.

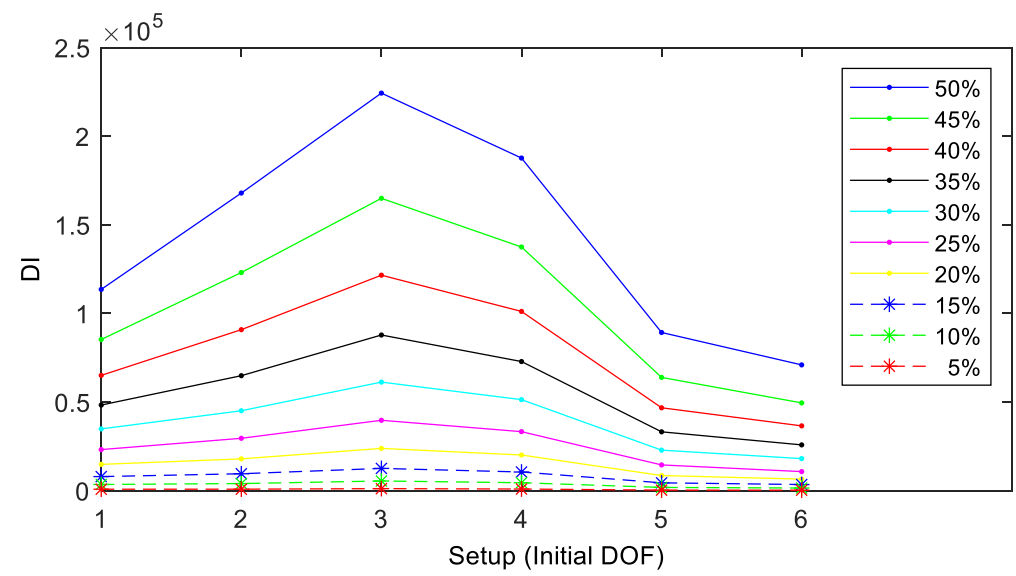

Figure 12 DI for different damage degrees and measured DOFs, damage in the $7^{\text {th }}$ element

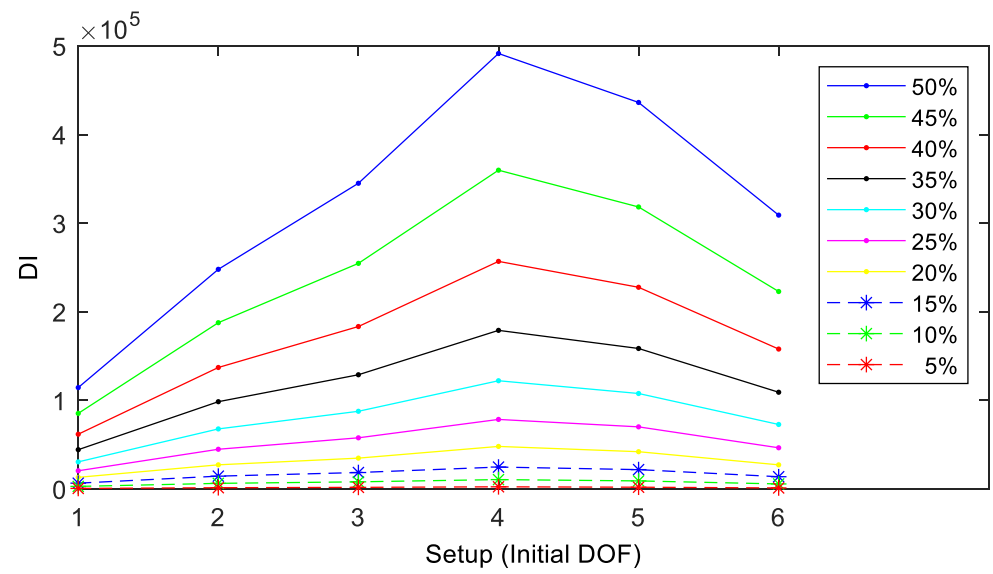

Figure 13 DI for different damage degrees and measured DOFs, damage in the $8^{\text {th }}$ element

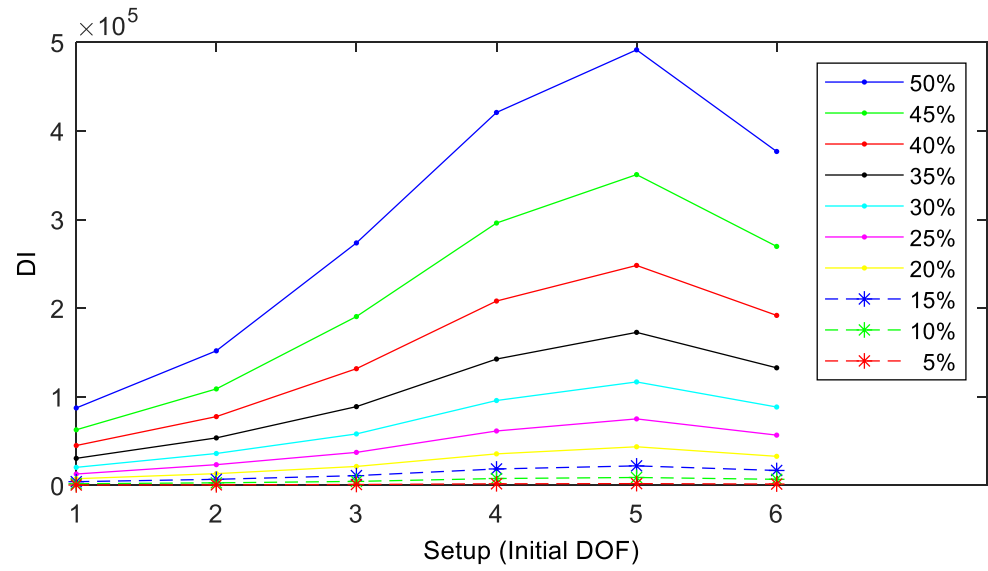

Figure 14 DI for different damage degrees and measured DOFs, damage in the $9^{\text {th }}$ element 


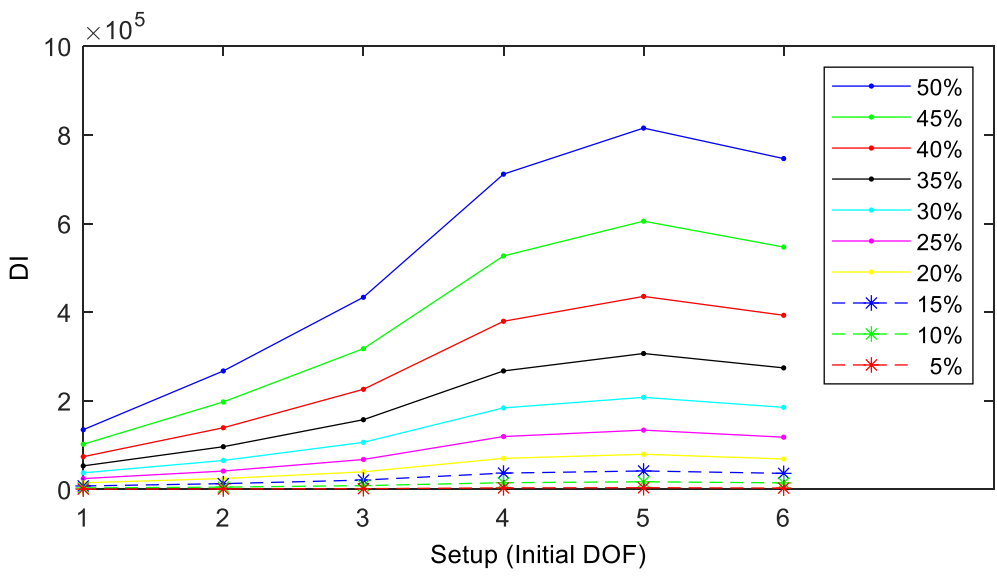

Figure 15 DI for different damage degrees and measured DOFs, damage in the $10^{\text {th }}$ element

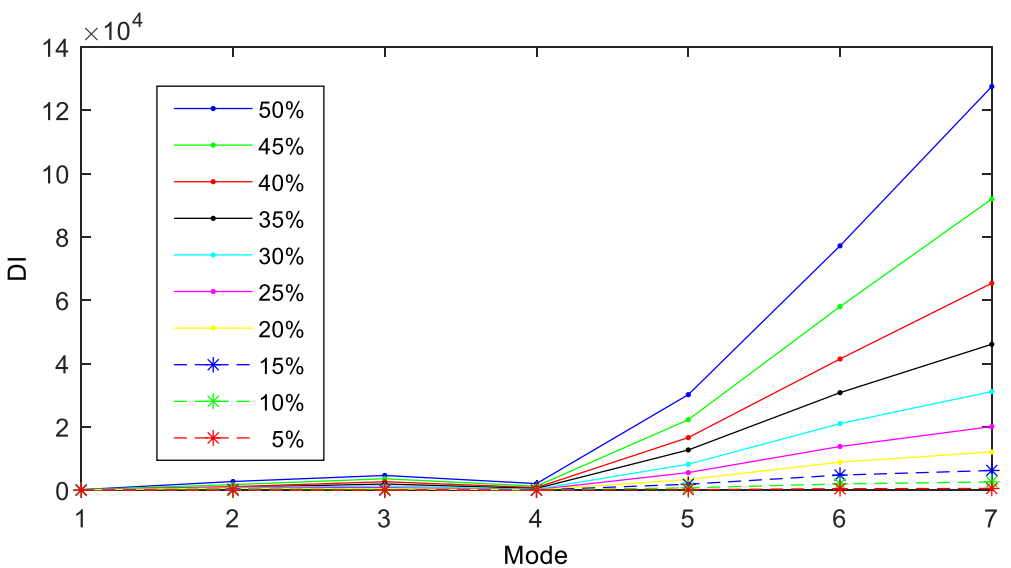

Figure 16 DI for different damage degrees and modes (only one mode used), damage in the $3^{\text {rd }}$ element

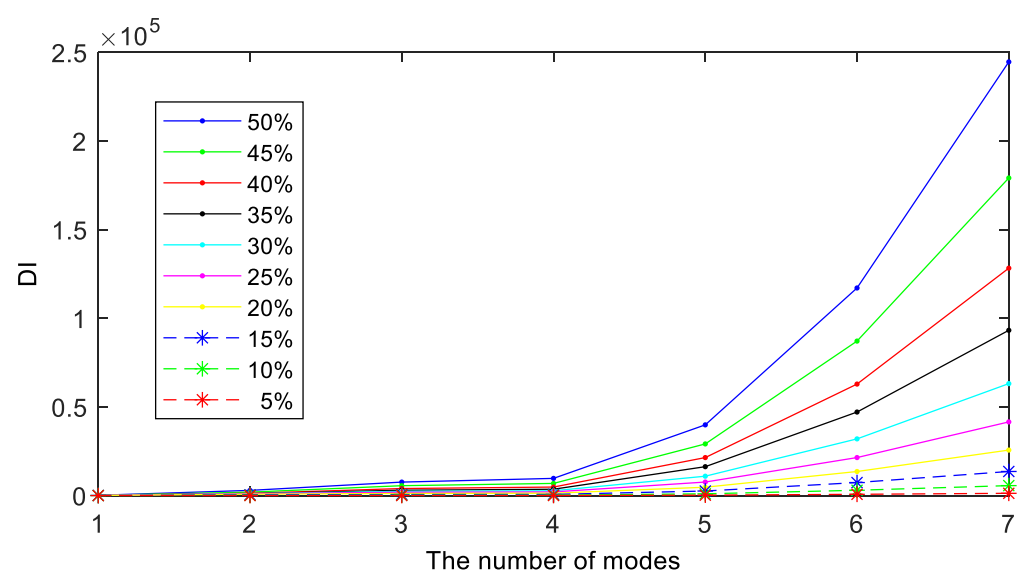

Figure 17 DI for different damage degrees and the number of modes used, damage in the $3^{\text {rd }}$ element

\subsection{Modes effect on DI}

In the above analysis, all the seven identified modes were used to calculate the DI for damage detection. In real applications, the number of modes that can be identified may 
depend on the objective structures, equipment and measurement noise. In this section, the effect of the modes used in the calculation of DI will be investigated. Figure 16 shows the DI for different damage degrees using the information of different modes, where the damage appears in the $3^{\text {rd }}$ element and all the nine DOFs are measured. In this figure, in different damage degrees, only the information of one mode, i.e., Mode 1 to Mode 7, was used individually. It is seen that the DIs calculated using Mode 1 to Mode 4 are all much smaller than those using Mode 5 to Mode 7. The DI tends to increase with the mode order. This means that the contributions of different modes to DI are different and the contribution of higher mode tends to be larger, e.g., in the case of $50 \%$ damage, the contribution of the $7^{\text {th }}$ mode is more than 15 times the $1^{\text {st }}$ mode. This is also verified by Figure 17, which shows the DI for different damage degrees and number of modes used when the damage appears in the $3^{\text {rd }}$ element. It is seen that the DI has an exponential rise when the number of modes used increases.

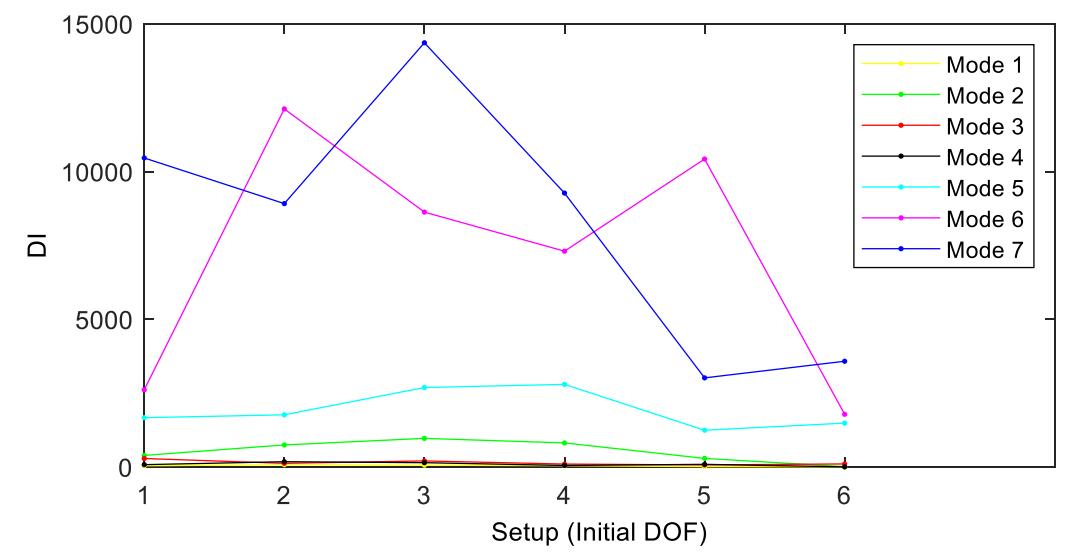

Figure 18 DI for different modes (only one mode used) and measured DOFs, $15 \%$ damage in the $3^{\text {rd }}$ element

Figure 18 shows the DI for different modes (only one mode used) with different setups (see Table 2), where $15 \%$ damage appears in the $3^{\text {rd }}$ element. In this figure, similar to Section 3.1, the mode effect on the different setups (measured DOFs) was studied. In each mode, the DI values for all the six setups could be obtained by the proposed method. It is seen that if only using the information of one mode, only the DIs calculated using Mode 2, Mode 5 or Mode 7 had the largest value in Setup 3 among all the setups. For other modes, their values in Setup 3 were not the largest value among all the setups. This observation is a little different from the results in Figure 8. This means that only 
the information of one single mode may not be enough to perform the damage detection. It is better to use as much useful information as possible.

\subsection{Damage appearing in two elements}

In the last section, damage appearing only in one element was investigated. In practice, the cases of damage appearing in two or more elements are commonly encountered. In this section, the cases with two damaged elements are studied. Figure 19 shows the DI for different damage degrees and measured DOFs, where damage appears in the $2^{\text {nd }}$ and $9^{\text {th }}$ elements. It is seen that corresponding to these two elements, two peaks were found in Setup 2 (the first location is Location 2) and Setup 5 (the last location is Location 9). This means that in this case the two instances of damage can also be observed by the DI. Figure 20 shows the DI for different damage degrees and measured DOFs, where damage appears in the $3^{\text {rd }}$ and $8^{\text {th }}$ elements. A similar observation can be found.

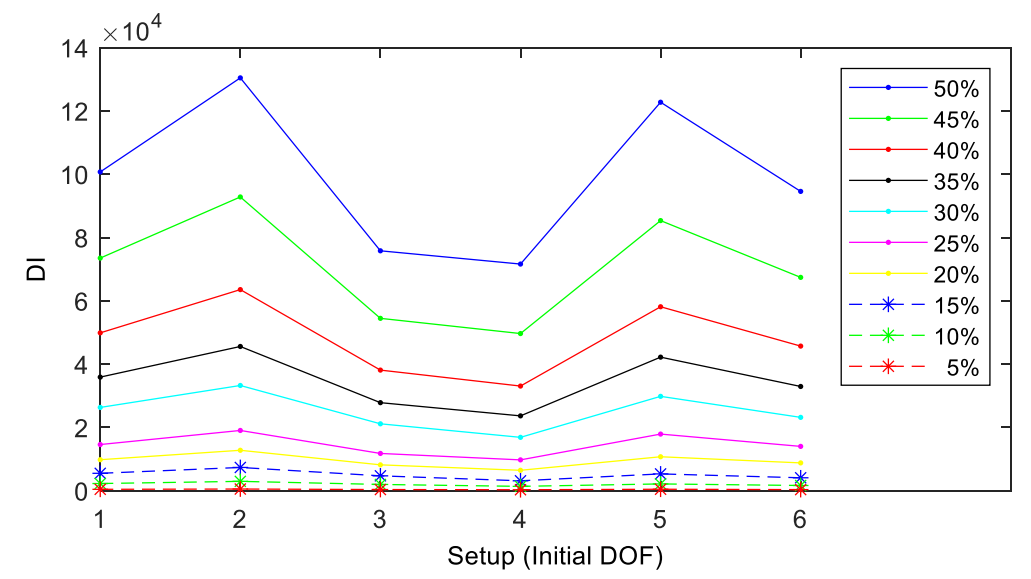

Figure 19 DI for different damage degrees and measured DOFs, damage in the $2^{\text {nd }}$ and $9^{\text {th }}$ elements

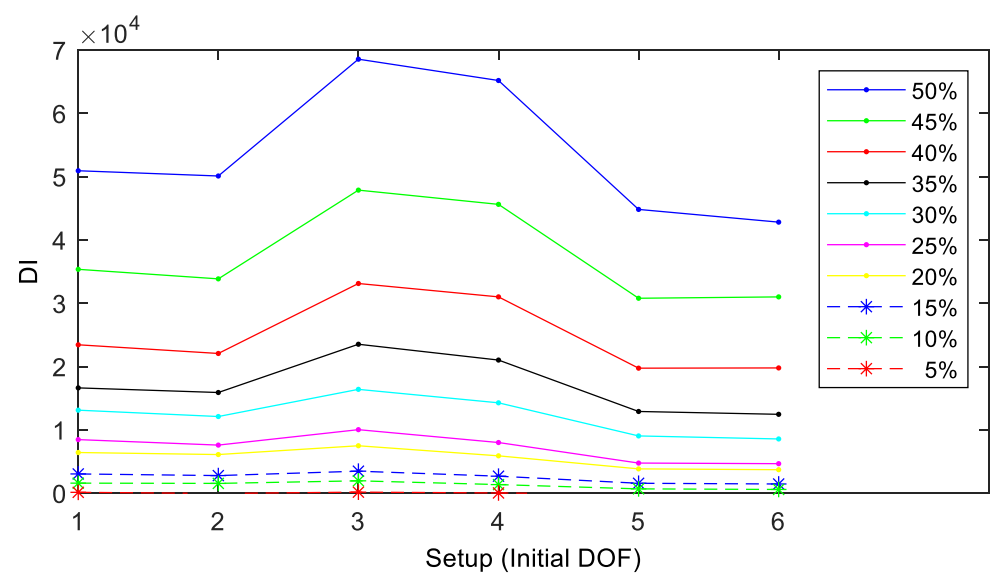

Figure 20 DI for different damage degrees and measured DOFs, damage in the $3^{\text {rd }}$ and $8^{\text {th }}$ elements 


\section{Applications}

The proposed method was applied to two real structures to detect the potential damage. The first was a truss bridge while the second was a frame structure.

\subsection{Truss bridge}

The first structure is located in Japan, which is a simply supported bridge about $60 \mathrm{~m}$ long and $3.6 \mathrm{~m}$ wide, as shown in Figure 21. It was removed in 2012 after it had been used for 53 years. A series of field vibration tests was carried out to investigate the dynamic properties of the bridge before it was removed [45]. Artificial damages were allowed to be designed to simulate different cases for the purpose of damage detection. Five scenarios were designed, including Case 1: Intact bridge, Case 2: Half cut in vertical member at mid-span, Case 3: Full cut in vertical member at mid-span, Case 4: Recovery of the cut member at mid-span, Case 5: Full cut in vertical member at $5 / 8^{\text {th }}$ span. In Case 2 and Case 3, the vertical member was the same as shown in Figure 22a. In Case 4, an attempt was made to recover the full cut member in Case 3 by using a jack to make the gap shorter and then steel plates were welded, as shown in Figure 22b. After the recovery, another member at $5 / 8^{\text {th }}$ span was fully cut in Case 5. Please refer to [45] for the detailed damage scenario information.

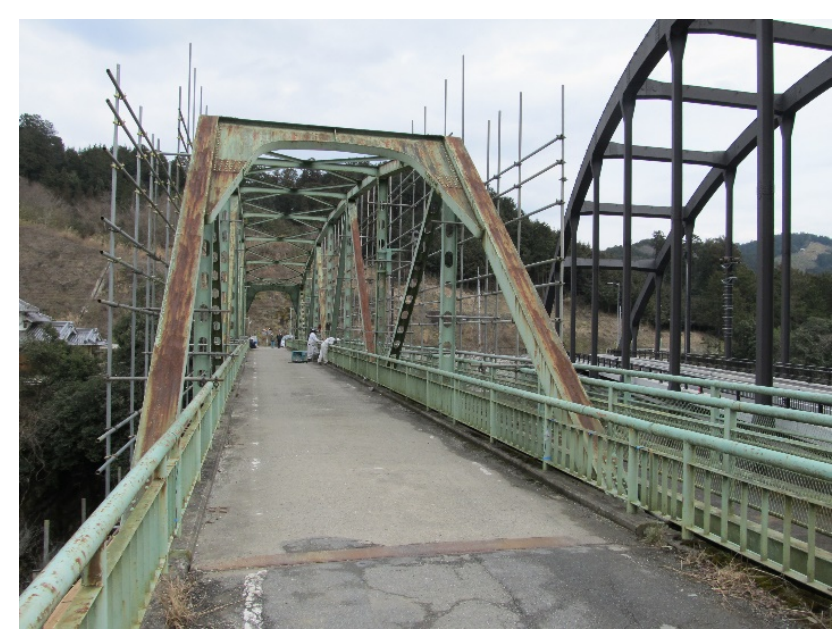

Figure 21 Overview of the bridge 


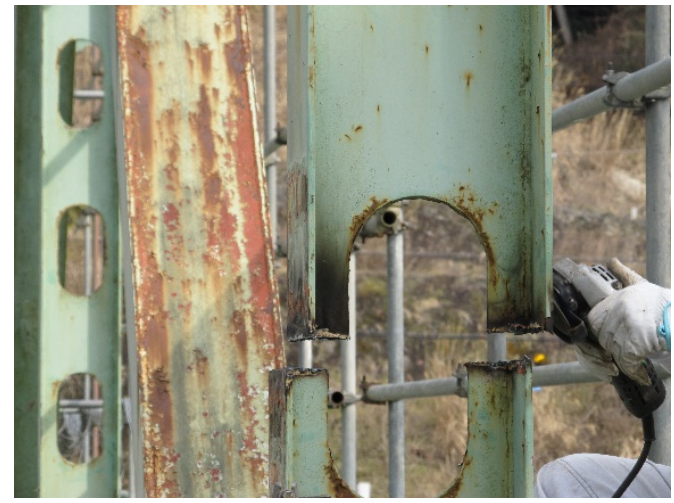

a. Full cut member in Case 3

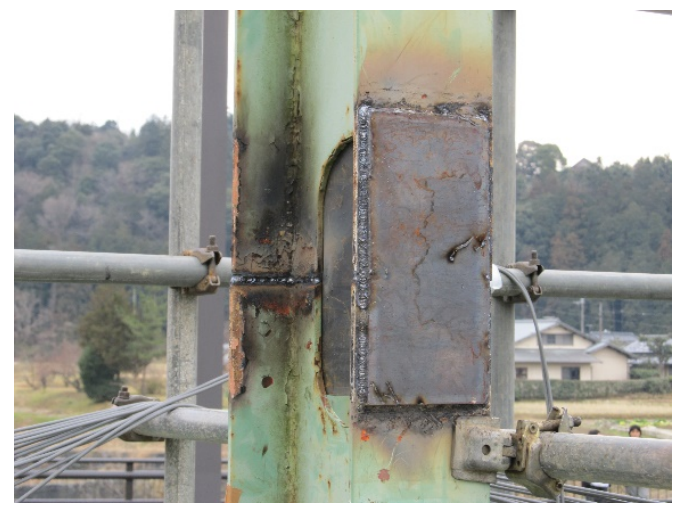

b. Recovered member in Case 4

Figure $22 \mathrm{Cut}$ and recovered vertical member in the mid-span

In order to measure the structural responses in different cases, eight sensors were installed on the bridge deck and the sensor locations were all around the damage area, as shown in Figure 1 of [45], where five sensors (A1 to A5) were put on the damaged side, while the other three (A6 to A8) were put on the other side. Only the vertical accelerations were measured with a sampling rate of $200 \mathrm{~Hz}$. Two kinds of field tests were carried out, including ambient vibration tests and vehicle-induced vibration tests. Note that during the field tests, the bridge was already closed and no other vehicles could pass the bridge. In this study, only ambient vibration responses were used. Figure 23 shows the PSD spectra of the data in Case 1. Clear peaks can be found below $12 \mathrm{~Hz}$, especially for the lower modes. The potential modes were selected and identified by the Fast Bayesian FFT method.

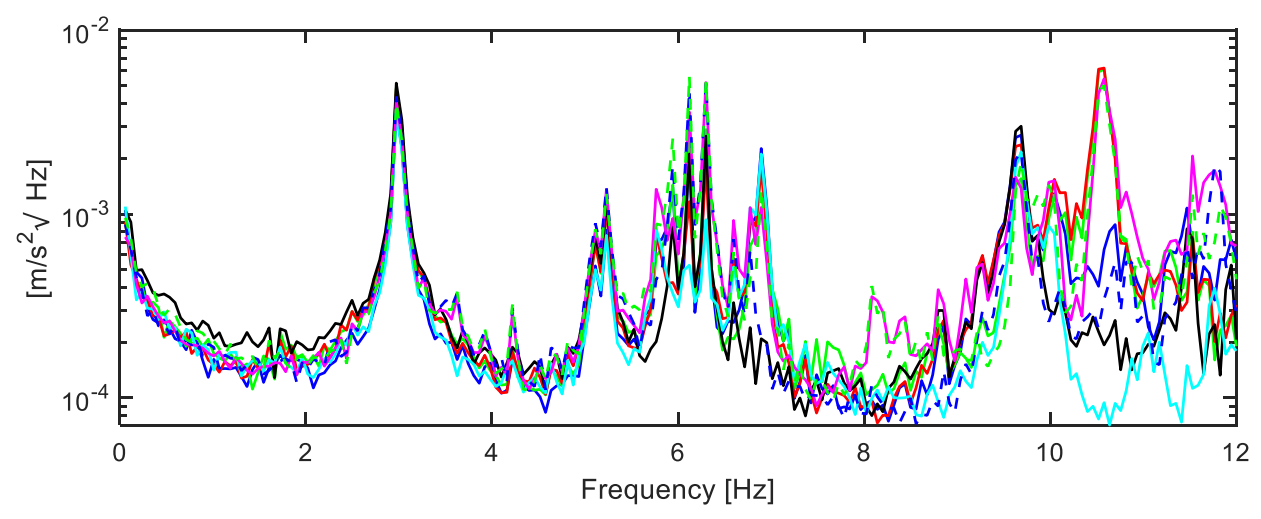

Figure 23 PSD spectra of the data in Case 1 
Table 3 Modal parameters identified in Case 1

\begin{tabular}{|c|c|c|c|c|c|c|}
\hline Mode & 1 & 2 & 3 & 4 & 5 & 6 \\
\hline $\begin{array}{c}\text { Natural frequency } \\
(\mathrm{Hz})\end{array}$ & 2.995 & 5.104 & 5.222 & 6.898 & 9.658 & 10.561 \\
\hline COV (\%) & 0.04 & 0.06 & 0.06 & 0.04 & 0.04 & 0.03 \\
\hline Damping ratio (\%) & 0.14 & 0.33 & 0.35 & 0.18 & 0.32 & 0.24 \\
\hline COV (\%) & 31.8 & 23.3 & 21.8 & 21.8 & 13.3 & 14.0 \\
\hline
\end{tabular}

Table 4 Modal parameters identified in Case 2

\begin{tabular}{|c|c|c|c|c|c|c|}
\hline Mode & 1 & 2 & 3 & 4 & 5 & 6 \\
\hline $\begin{array}{c}\text { Natural frequency } \\
(\mathrm{Hz})\end{array}$ & 2.992 & 5.150 & 5.202 & 6.904 & 9.693 & 10.626 \\
\hline COV (\%) & 0.08 & 0.03 & 0.05 & 0.05 & 0.05 & 0.03 \\
\hline Damping ratio (\%) & 0.30 & 0.07 & 0.19 & 0.32 & 0.33 & 0.15 \\
\hline COV (\%) & 26.7 & 46.6 & 28.4 & 18.1 & 17.0 & 20.1 \\
\hline $\begin{array}{c}\text { MAC } \\
(\text { Cases 1 and 2) }\end{array}$ & 1.0000 & 0.9995 & 0.9996 & 0.9993 & 0.9988 & 0.9986 \\
\hline
\end{tabular}

Table 5 Modal parameters identified in Case 3

\begin{tabular}{|c|c|c|c|c|c|c|}
\hline Mode & 1 & 2 & 3 & 4 & 5 & 6 \\
\hline $\begin{array}{c}\text { Natural frequency } \\
(\mathrm{Hz})\end{array}$ & 2.888 & 4.973 & 5.142 & 6.883 & 9.680 & 10.606 \\
\hline COV (\%) & 0.06 & 0.09 & 0.07 & 0.02 & 0.03 & 0.04 \\
\hline Damping ratio (\%) & 0.19 & 0.52 & 0.35 & 0.09 & 0.15 & 0.30 \\
\hline COV (\%) & 29.8 & 19.6 & 24.1 & 26.9 & 18.3 & 14.6 \\
\hline $\begin{array}{c}\text { MAC } \\
\text { (Cases 1 and 3) }\end{array}$ & 0.9991 & 0.9926 & 0.9982 & 0.9995 & 0.9945 & 0.9975 \\
\hline
\end{tabular}

Table 6 Modal parameters identified in Case 4

\begin{tabular}{|c|c|c|c|c|c|c|}
\hline Mode & 1 & 2 & 3 & 4 & 5 & 6 \\
\hline $\begin{array}{c}\text { Natural frequency } \\
(\mathrm{Hz})\end{array}$ & 2.983 & 5.136 & 5.202 & 6.873 & 9.572 & 10.510 \\
\hline COV (\%) & 0.10 & 0.04 & 0.05 & 0.05 & 0.04 & 0.04 \\
\hline Damping ratio (\%) & 0.51 & 0.12 & 0.17 & 0.24 & 0.23 & 0.35 \\
\hline COV (\%) & 21.6 & 32.8 & 29.0 & 24.8 & 16.5 & 14.9 \\
\hline $\begin{array}{c}\text { MAC } \\
\text { (Cases 1 and 4) }\end{array}$ & 0.9997 & 0.9996 & 0.9996 & 0.9992 & 0.9978 & 0.9982 \\
\hline
\end{tabular}


Table 7 Modal parameters identified in Case 5

\begin{tabular}{|c|c|c|c|c|c|c|}
\hline Mode & 1 & 2 & 3 & 4 & 5 & 6 \\
\hline $\begin{array}{c}\text { Natural frequency } \\
(\mathrm{Hz})\end{array}$ & 2.865 & 5.015 & 5.088 & 6.467 & 9.695 & 10.367 \\
\hline COV (\%) & 0.16 & 0.11 & 0.10 & 0.05 & 0.04 & 0.06 \\
\hline Damping ratio (\%) & 1.34 & 0.36 & 0.53 & 0.30 & 0.32 & 0.40 \\
\hline COV (\%) & 13.3 & 25.5 & 21.4 & 20.7 & 15.9 & 17.7 \\
\hline $\begin{array}{c}\text { MAC } \\
(\text { Cases 1 and 5) }\end{array}$ & 0.9976 & 0.9715 & 0.9893 & 0.9382 & 0.7002 & 0.7667 \\
\hline
\end{tabular}

Table 3 to Table 7 show the modal parameters identified in Case 1 to Case 5, respectively, including the natural frequency and damping ratio of each mode. In the proposed method, for the purpose of comparing the difference of the same modes in different statuses, it is necessary for the same mode in different cases to be selected. Therefore, considering this fact, only six common modes existing in all the cases were selected, although from Figure 23, there are around 10 modes below $12 \mathrm{~Hz}$. The way to select the same mode is the MAC values between Case $i(i=2,3,4,5)$ and Case 1 , as shown in the last row of each table. It is worth mentioning that for Case 2 to Case 4 , the MAC values are all larger than 0.99; however, in Case 5, the MAC values are much lower, especially for Mode 5 and Mode 6. The natural frequencies of the corresponding modes from Case 1 to Case 5 vary obviously. For Mode 1 and Mode 3, the value tends to decrease from Case 1 to Case 3, and then increase in Case 4. From Case 4 to Case 5, it decreases again. These two modes change following our intuition that the stiffness reduction may cause the decrease of the natural frequency. However, for other modes, it is difficult to observe this phenomenon, especially for the higher modes, and it is seen that some natural frequency tends to increase when there is larger damage. This means that for a real structure, it is really difficult to judge the damage status according to the change of natural frequency directly. For the damping ratios, no trend could be found. One possible reason is that the damping ratios have larger uncertainties (COV) as shown in the fifth row of each table. As mentioned, from Case 1 to Case 4, the MAC values are all larger than 0.99 . This indicates that it is also difficult to observe the damage from the mode shape directly. 
Table 8 Damage indicators $\left(\times 10^{5}\right)$ calculated from Case 2 to Case 5

\begin{tabular}{|c|c|c|c|c|}
\hline Cases & 2 & 3 & 4 & 5 \\
\hline $\begin{array}{c}\text { DI (Damping } \\
\text { accounted) }\end{array}$ & 0.084 & 0.390 & 0.105 & 7.143 \\
\hline $\begin{array}{c}\text { DI (Damping not } \\
\text { accounted) }\end{array}$ & 0.085 & 0.391 & 0.106 & 7.158 \\
\hline
\end{tabular}

Table 8 shows the damage indicators calculated by the proposed method using the modal parameters identified in all the cases. Case 1 was taken as the undamaged case and the DI values were all determined based on Case 1. To investigate the effect of damping ratios on the damage detection, both the results with and without damping ratios taken into account are calculated in this table. For the latter result without damping ratios accounted, the damping ratios were kept unchanged from hypotheses $\mathrm{H}_{0}$ to $\mathrm{H}_{1}$. For the former case, when the damping is considered, it is seen that from Case 2 (half cut) to Case 3 (full cut), following the increase of damage extent, the DI increased significantly. This is because in the case of half cut, although there will be some loss of stiffness, the other half of the member can still bear the load, making load transfer possible. When the vertical member is fully cut, the stiffness of the whole bridge will be re-distributed, which may cause an obvious increase of the DI. In Case 4 , although the damaged vertical member was recovered, the redistribution of the stiffness was difficult to recover in a short time and some change will be permanent. This results in the DI value being a little higher than Case 2, although it is obviously lower than Case 3. In Case 5, i.e., the vertical member at $5 / 8^{\text {th }}$ span was fully cut, the stiffness of the whole structure was re-distributed again, and also considering the residual recovery effect in Case 4 , it is reasonable that the DI had the largest value. In summary, the damage behaviour in all the cases was reflected by the proposed damage indicator. For the case without damping considered, it is seen that there was some difference compared to the ones when damping was considered. However, the difference is not obvious. This shows that the damping ratio is not sensitive in this structure. The mechanics of the damping ratio on the damage detection is worth further investigation. Note that the change of PSD of modal force and PSD of prediction error will not be considered since these two parameters are mainly affected by the input and 
the environment around, respectively.

To further investigate the proposed method, the results obtained by the proposed method were compared with the ones obtained in [45] using a Mahalanobis distance method. Both methods can identify the damage by considering all the useful modal parameters. It is worth mentioning that the proposed method is more sensitive to the small damage (Case 2). This may be due to the fact that the uncertainty of the modal parameters can also be considered by the proposed method, which helps to judge whether the change of modal parameters is due to the identification accuracy or the structure stiffness variation. The effect of stiffness redistribution after recovery of the damaged member can also be detected by the proposed method.

\subsection{Frame structure}

In this part, a benchmark structure developed by the International Association for Structural Control (IASC) and the Dynamics Committee of the ASCE Engineering Mechanics Division is used to illustrate the problem. The structure is a 4-storey, $2.5 \mathrm{~m}$ $\times 2.5 \mathrm{~m}$ in plan steel-frame scaled building with a height of $3.6 \mathrm{~m}$. The bracing system in each bay is composed of two threaded steel rods, which can be used to simulate the structural damage by removing them. For more details about the structure, please refer to [46]. Three kinds of tests were carried out to collect the structural responses for damage detection, including ambient vibration test, shaker test and hammer test. In total, 16 accelerometers were used to perform the measurement, with 15 installed on the structures from the base to the top floor and three sensors on each floor, and one installed on the shaker to record the shaker excitation. The sensitivity of the sensors instrumented on the building is 5 volts $/ \mathrm{g}$. In the ambient vibration test, the sampling frequency was $250 \mathrm{~Hz}$. In total, nine cases were designed as shown in [46]. In this study, three cases with ambient vibration tests performed were used, i.e., Case 1, Fully braced configuration; Case 3, Removed braces on all floors in one bay on the southeast corner; Case 5, Removed braces on the $1^{\text {st }}$ floor in one bay on the southeast corner.

Figure 24 to Figure 26 show the PSD spectra below $30 \mathrm{~Hz}$ of the measured data of Case 
1 to Case 5, respectively. Some clear peaks can be found in all the three spectra. It is seen that the magnitude and the shape of the peaks in Case 1 and Case 5 are similar, while a large discrepancy can be found in Case 3. This is because from Case 1 to Case 5 , only the braces on the $1^{\text {st }}$ floor in one bay on the southeast corner were removed, while from Case 1 to Case 3, braces on all floors in one bay on the southeast corner were removed. The latter case has much more change, which resulted in the obvious change in the structural responses. The first eight modes were focused on.

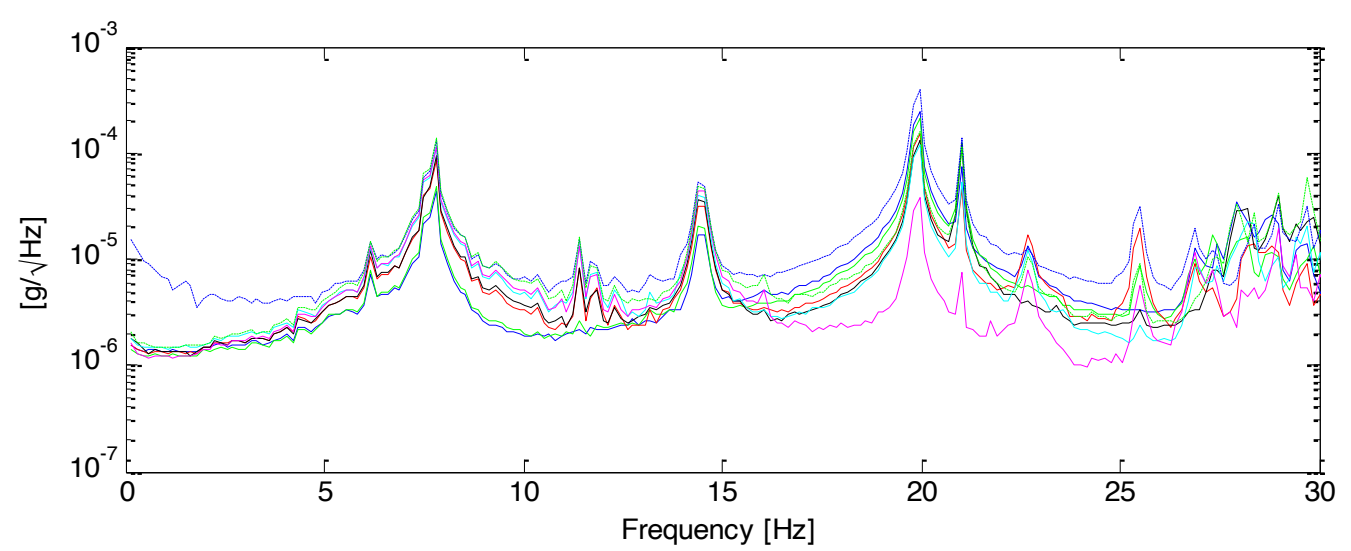

Figure 24 PSD spectra of the measured data in Case 1

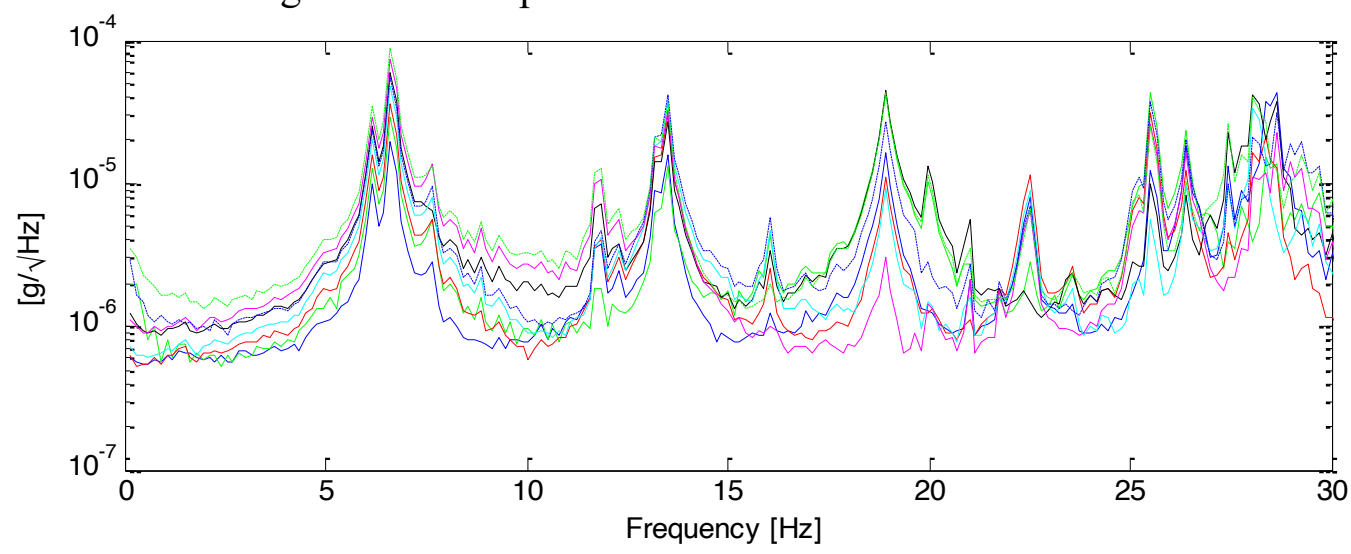

Figure 25 PSD spectra of the measured data in Case 3

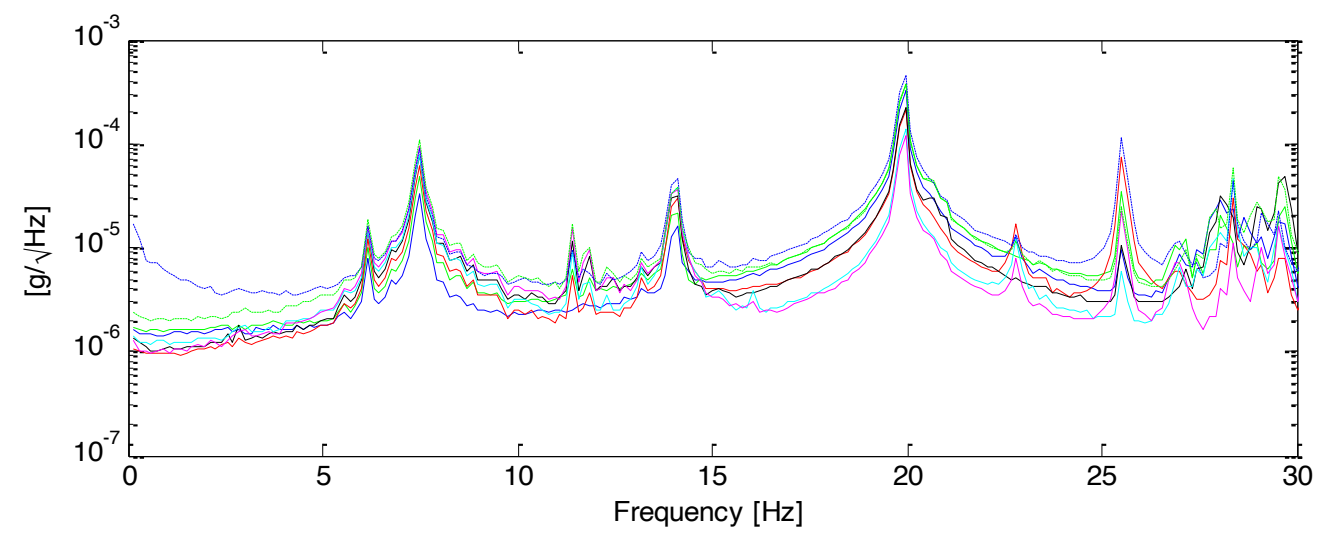

Figure 26 PSD spectra of the measured data in Case 5 
Table 9 Modal parameters identified in Case 1

\begin{tabular}{|c|c|c|c|c|c|c|c|c|}
\hline Mode & 1 & 2 & 3 & 4 & 5 & 6 & 7 & 8 \\
\hline $\begin{array}{c}\text { Natural } \\
\text { frequency } \\
(\mathrm{Hz})\end{array}$ & 6.164 & 7.766 & 11.374 & 11.788 & 14.481 & 21.013 & 22.696 & 25.477 \\
\hline COV (\%) & 0.12 & 0.06 & 0.02 & 0.01 & 0.02 & 0.01 & 0.03 & 0.02 \\
\hline $\begin{array}{c}\text { Damping } \\
\text { ratio (\%) }\end{array}$ & 1.10 & 0.43 & 0.05 & 0.03 & 0.15 & 0.04 & 0.30 & 0.17 \\
\hline COV (\%) & 13.9 & 17.1 & 31.8 & 39.0 & 17.6 & 24.8 & 10.9 & 12.2 \\
\hline
\end{tabular}

Table 10 Modal parameters identified in Case 3

\begin{tabular}{|c|c|c|c|c|c|c|c|}
\hline Mode & 1 & 2 & 3 & 5 & 6 & 7 & 8 \\
\hline $\begin{array}{c}\text { Natural frequency } \\
(\mathrm{Hz})\end{array}$ & 6.126 & 6.648 & 7.616 & 11.776 & 18.915 & 22.458 & 25.551 \\
\hline COV (\%) & 0.07 & 0.06 & 0.09 & 0.02 & 0.03 & 0.02 & 0.01 \\
\hline Damping ratio (\%) & 0.48 & 0.37 & 0.78 & 0.08 & 0.27 & 0.20 & 0.04 \\
\hline COV (\%) & 16.7 & 16.9 & 15.7 & 25.2 & 11.6 & 12.3 & 24.1 \\
\hline $\begin{array}{c}\text { MAC } \\
\text { (Cases 1 and 3) }\end{array}$ & 0.984 & 0.980 & 0.962 & 0.909 & 0.971 & 0.994 & 0.847 \\
\hline
\end{tabular}

Table 11 Modal parameters identified in Case 5

\begin{tabular}{|c|c|c|c|c|c|c|c|c|}
\hline Mode & 1 & 2 & 3 & 4 & 5 & 6 & 7 & 8 \\
\hline $\begin{array}{c}\text { Natural } \\
\text { frequency } \\
(\mathrm{Hz})\end{array}$ & 6.150 & 7.464 & 11.378 & 11.786 & 14.038 & 20.625 & 22.795 & 25.540 \\
\hline COV (\%) & 0.06 & 0.05 & 0.01 & 0.02 & 0.02 & 0.03 & 0.03 & 0.01 \\
\hline $\begin{array}{c}\text { Damping } \\
\text { ratio (\%) }\end{array}$ & 0.41 & 0.37 & 0.03 & 0.08 & 0.15 & 0.27 & 0.25 & 0.03 \\
\hline COV (\%) & 17.4 & 15.1 & 39.8 & 26.6 & 17.5 & 15.2 & 12.5 & 29.0 \\
\hline $\begin{array}{c}\text { MAC } \\
\text { Cases 1 } \\
\text { and 5) }\end{array}$ & 0.999 & 0.997 & 0.942 & 0.915 & 0.997 & 0.974 & 0.999 & 0.997 \\
\hline
\end{tabular}

Table 9 to Table 11 show the modal parameters identified by the Fast Bayesian FFT method using the data from Case 1, Case 3 and Case 5, respectively. Consistent with the observation in the PSD spectral, it is seen that in Case 1 and Case 5, the changes of 
natural frequencies are smooth and the MAC can correspond to the order of the modes with the values all larger than 0.91. However, for Case 1 and Case 3, there was a significant change of natural frequencies for the corresponding modes and Mode 4 of Case 3 could not be identified. It is seen that for Case 3 in Table 10, in the spectra (Figure 24) from $5^{\text {th }}(11.776 \mathrm{~Hz})$ to $6^{\text {th }}(18.915 \mathrm{~Hz})$ mode, there is also a clear peak around $14 \mathrm{~Hz}$, and this mode can also be identified well. However, from the MAC value, it is difficult to find a mode in Case 1 having a higher MAC value with this mode. Therefore, the information of this mode was not used in damage detection.

Table 12 Setup information

\begin{tabular}{|l|l|l|l|l|}
\hline Channels & 1 & 2 & 3 & 4 \\
\hline Setup 1 & NS1-1 & NS1-2 & NS2-1 & NS2-2 \\
\hline Setup 2 & NS2-1 & NS2-2 & NS3-1 & NS3-2 \\
\hline Setup 3 & NS3-1 & NS3-2 & NS4-1 & NS4-2 \\
\hline
\end{tabular}

Table 13 Damage indicators $\left(\times 10^{6}\right)$ calculated in Cases 3 and 5

\begin{tabular}{|c|c|c|c|}
\hline Setup & 1 & 2 & 3 \\
\hline Case 3 & 4.8843 & 3.7128 & 4.3465 \\
\hline Case 5 & 7.1328 & 1.8286 & 1.2768 \\
\hline
\end{tabular}

For other corresponding modes, the MAC values between Case 1 and Case 3 tended to decrease. This means that the damage in Case 3 changed the distribution of the stiffness of the structure and then the modal properties dramatically. It is also interesting to see that the damping ratios of the steel structures were all very small (around or less than 1\%). After damage, the damping ratios of more than half of the modes tended to decrease. However, the damping ratio has a larger uncertainty as reflected in the COV values $(10 \%$ to $30 \%)$ in the tables. It is difficult to judge whether the variation of the damping ratio is due to the damage or not. In this study, only the channels in the NS direction were used for damage detection, where on each floor, two un-axial accelerometers were installed in the middle of the east and west sides, respectively. To detect the damage, the eight channels were separated into three setups, i.e., in Setup 1, the four sensors on the first and second floors were selected, in Setup 2, the four sensors on the second and third floors were selected, and in Setup 3, the four sensors on the 
third and fourth floors were selected. The setup information can be seen in Table 12. In this table, for each number, the first two letters denote the direction, the first number denotes the floor number, and the second number denotes the location number. For example, NS1-2 denotes the second location on the first floor in the NS direction.

Table 13 shows the DI values calculated in Cases 3 and 5 based on the proposed method. It is seen that in Case 3, the DI values for different setups were similar while in Case 5, the DI values decreased obviously from Setup 1 to Setup 3. This is consistent with the damage cases, since in Case 3, the damage was similar from Floor 1 to Floor 4, while in Case 5, the damage only appeared on the first floor, resulting in the phenomenon that the indicators decrease when the sensors are far away from the damage. From the observation above, the damage can be reflected by the damage indicator in these two damage cases.

\section{Conclusions}

This paper presents the work on developing a novel damage indicator in the frequency domain based on the Bayes factor using ambient vibration data. One merit of the proposed method is that by selecting frequency bands that contain the modes information for damage detection, useless or unrelated information will be removed. Furthermore, in the ambient vibration tests, the excitations are all random and the signal to noise ratio is small, which makes uncertainties of the modal parameters identified from the ambient data inevitably exist. If the damage is small, it is difficult to judge whether the change of modal parameters is due to the identification accuracy or the structural damage. The proposed method was developed to solve this problem. In the likelihood function and the prior PDF, which are used to construct the novel damage indicator, the MPVs of modal parameters and the associated posterior uncertainty can be both considered.

In addition to the natural frequencies (commonly used in traditional damage detection methods), this new damage indicator can also consider the variation of damping ratio and mode shape. This makes it possible to detect the damage location by changing the 
measured locations using the mode shape information. A series of numerical examples was designed to illustrate the proposed method. In the example, different factors such as the damage extent, damage locations and the number of modes used were investigated and it was found that the proposed method is sensitive to these factors. Finally, the proposed method was applied in the damage detection of a truss bridge and an ASCE benchmark steel frame structure. For the truss bridge, five different cases were investigated. By taking Case 1 as the undamaged case, the DI values for the other four cases were calculated using the proposed method. It is seen that the DI values increase when the damage increases and the DI is also sensitive in the redistribution of the structure stiffness. For the frame structure, two different cases were studied, including Case 3 with damage on all the floors and Case 5 with damage on the first floor. It is seen that the damage indicators are similar in all the three setups of Case 3 and they decrease obviously in the three setups of Case 5. The damage can be reflected by the proposed method.

In this study, the single damage case was mainly focused on; however, in real applications, two or more damage locations also appear with multiple damage states. It is worthy to investigate these multiple damage cases in the future by increasing the measured DOFs. The effect of boundary conditions on damage detection may also be considered in the prior information. The computational burden should be still manageable since the time to conduct modal identification with large amounts of measured DOFs is still under control by the Fast Bayesian FFT method. In the current field examples, it is difficult to perform the investigation of damage localization due to the sensor locations or arrangement, so field vibration tests will be designed to conduct this research. Furthermore, the environmental effects such as temperature will also be studied.

\section{Acknowledgement}

This work is supported by the JSPS Fellowship (P17371), the National Natural Science Foundation of China (Grant No: 51878484) and Grant-in-Aid for JSPS Fellows (Grant No: 17F17371). The financial supports are greatly acknowledged. The International 
Association for Structural Control (IASC) and the Dynamics Committee of the ASCE

Engineering Mechanics Division are also acknowledged for providing the data in the example of the benchmark problem.

\section{References}

[1] Chatzi E \& Smyth, AW. Particle filter scheme with mutation for the estimation of time-invariant parameters in structural health monitoring applications, Structural Control and Health Monitoring. 2013, 20(7), 1081-95.

[2] Yang Y \& Nagarajaiah S. Structural damage identification via a combination of blind feature extraction and sparse representation classification, Mechanical Systems \& Signal Processing. 2014, 45(1), 1-23.

[3] Sun H, Betti R. A hybrid optimization algorithm with Bayesian inference for probabilistic model updating. Comput.-Aided Civ. Inf. 2015, 30 (8): 602-619.

[4] Ding ZH, Li J, Hao H. Structural damage identification with uncertain modelling error and measurement noise by clustering based tree seeds algorithm. Engineering. Structures, 2019, 185: 301-314.

[5] Huseynov F, Kim CW, Obrien EJ, Brownjohn JM, Hester D \& Chang KC. Bridge Damage Detection Using Rotation Measurements - Experimental Validation. Mechanical Systems and Signal Processing. 2020, 135, 106380.

[6] Zhang Y, Kim CW, Zhang L, Bai Y, Yang H, Xu X, and Zhang Z. Long term structural health monitoring for old deteriorated bridges: a copula-ARMA approach. Smart Structures and Systems, 2020, 25(3), 285-299.

[7] Cha YJ, Choi W, and Büyüköztürk O. Deep learning - based crack damage detection using convolutional neural networks. Computer - Aided Civil and Infrastructure Engineering, 2017, 32(5): 361-378.

[8] Eraky A, Anwar AM, Saad A, et al. Damage detection of flexural structural systems using damage index method-Experimental approach. Alexandria Engineering Journal, 2015, 54(3): 497-507.

[9] Ding Y, Yao X, Wang S, Zhao X. Structural damage assessment using improved Dempster-Shafer data fusion algorithm. Earthquake Engineering and Engineering Vibration, 2019, 18(2): 395-408.

[10] Song LF, Xu B, Kong XJ, Zou DG, Pang R, Yu X, Zhang Z. Three-dimensional slope dynamic stability reliability assessment based on the probability density evolution method. Soil Dynamics and Earthquake Engineering, 2019, 120: 360-368.

[11]Ciambella J, Vestroni F. The use of modal curvatures for damage localization in beam-type structures. Journal of Sound and Vibration, 2015, 340: 126-137. 
[12]Zhang FL, Au SK and Ni YC. Two-stage Bayesian system identification with Gaussian discrepancy model. Structural Health Monitoring, 2020, https://doi.org/10.1177/1475921720933523.

[13] Yang JH, Lam HF. An efficient adaptive sequential Monte Carlo method for Bayesian model updating and damage detection. Structural Control and Health Monitoring, 2018, 25(12): e2260.

[14]Rucka M, Wilde K. Application of continuous wavelet transform in vibration based damage detection method for beams and plates. Journal of Sound and Vibration, 2006, 297(3-5): 536-550.

[15]Lam HF, Ng CT. A Probabilistic Method for the Detection of Obstructed Cracks of Beam-type Structures Using Spatial Wavelet Transform. Probabilistic Engineering Mechanics, 2008, 23(2-3): 237-245.

[16]Bakhary N, Hao H, Deeks AJ. Damage detection using artificial neural network with consideration of uncertainties. Engineering Structures, 2007, 29(11): 28062815.

[17]Lam HF, Ng CT. The Selection of Pattern Features for Structural Damage Detection Using an Extended Bayesian ANN Algorithm. Engineering Structures, 2008, 30(10): 2762-2770.

[18]Zhou, X. T., Ni YQ, and Zhang FL. Damage localization of cable-supported bridges using modal frequency data and probabilistic neural network. Mathematical Problems in Engineering 2014. Article ID 837963.

[19]Kessler SS, Spearing SM, Soutis C. Damage detection in composite materials using Lamb wave methods. Smart materials and structures, 2002, 11(2): 269.

[20]Ng CT. A Two-stage Approach for Quantitative Imaging of Laminar Damage in Plates Using Lamb Waves. Earthquakes and Structures, An International Journal, 2015, 8(4): 821-841.

[21]Zou D, Du C, Liu T, Li W. Effects of temperature on the performance of the piezoelectric-based smart aggregates active monitoring method for concrete structures. Smart Materials and Structures, 2019, 28: 035016

[22] Yu L, Giurgiutiu V. In situ 2-D piezoelectric wafer active sensors arrays for guided wave damage detection. Ultrasonics, 2008, 48(2): 117-134.

[23]Ng CT. On the Selection of Advanced Signal Processing Techniques for Guided Wave Damage Identification Using a Statistical Approach. Engineering Structures, 2014, 67: 50-60.

[24] Yuen KV. Bayesian Methods for Structural Dynamics and Civil Engineering. John Wiley \& Sons, ISBN: 978-0-470-82454-2. 2010.

[25] Ni YC, Zhang FL. Uncertainty quantification in fast Bayesian modal identification using forced vibration data considering the ambient effect. Mechanical Systems and Signal Processing, 2020, https://doi.org/10.1016/j.ymssp.2020.107078 
[26] Au SK. Operational Modal Analysis Modeling, Bayesian Inference, Uncertainty Laws. Springer. 2017.

[27] Au SK, Zhang FL, Ni YC. Bayesian operational modal analysis: theory, computation, practice. Computers \& Structures, 2013, 126: 3-14.

[28]Au SK, Zhang FL. On assessing the posterior mode shape uncertainty in ambient modal identification. Probabilistic Engineering Mechanics, 2011, 26(3): 427-434.

[29] Au SK. Fast Bayesian FFT method for ambient modal identification with separated modes. Journal of Engineering Mechanics, 2011, 137(3): 214-226.

[30] Au SK. Fast Bayesian ambient modal identification in the frequency domain, Part I: Posterior most probable value. Mechanical Systems and Signal Processing, 2012, 26: 60-75.

[31] Au SK. Fast Bayesian ambient modal identification in the frequency domain, Part II: posterior uncertainty. Mechanical Systems and Signal Processing, 2012, 26: 7690.

[32]Ni YC, Zhang FL. Fast Bayesian frequency domain modal identification from seismic response data. Computers \& Structures, 2019, 212: 225-235.

[33]Ni YC, Zhang FL. Fast Bayesian approach for modal identification using forced vibration data considering the ambient effect. Mechanical Systems and Signal Processing, 2018, 105: 113-128.

[34]Ni YC, Zhang QW, Liu JF. Dynamic Property Evaluation of a Long-Span CableStayed Bridge (Sutong Bridge) by a Bayesian Method. International Journal of Structural Stability and Dynamics, 2019, 19(01): 1940010.

[35] Ni Y, Lu X, Lu W. Operational modal analysis of a high-rise multi-function building with dampers by a Bayesian approach. Mechanical Systems and Signal Processing, 2017, 86: 286-307.

[36]Zhang FL, Ventura CE, Xiong HB, Lu WS, Pan YX, Cao JX. Evaluation of the dynamic characteristics of a super tall building using data from ambient vibration and shake table tests by a Bayesian approach. Structural Control and Health Monitoring, 2018, 25(4): e2121.

[37]Kass, RE. Bayes factors in practice. Journal of the Royal Statistical Society: Series D (The Statistician) 1993, 42(5): 551-560.

[38]Kass RE, Raftery AE. Bayes factors. Journal of the American Statistical Association, 1995, 90(430): 773-795.

[39] Lavine M and Schervish MJ. Bayes factors: What they are and what they are not. The American Statistician, 1999, 53(2): 119-122.

[40]Jarosz AF and Wiley J. What are the odds? A practical guide to computing and reporting Bayes factors. The Journal of Problem Solving, 2014 7(1), 2.

[41]Dienes Z. How Bayes factors change scientific practice. Journal of Mathematical Psychology, 2016, 72: 78-89. 
[42] Goi Y, Kim CW. Bayesian outlier detection for health monitoring of bridges. Procedia engineering, 2017, 199: 2120-2125.

[43] Goi Y, Kim CW. Damage detection of a truss bridge utilizing a damage indicator from multivariate autoregressive model. Journal of Civil Structural Health Monitoring, 2017, 7(2): 153-162.

[44]Zhang F.L., Ni Y.Q. and Ni Y.C. Mode identifiability of a cable-stayed bridge based on a Bayesian method. Smart Structures and Systems, 2016, 17(3): 471-489.

[45]Chang KC, Kim CW. Modal-parameter identification and vibration-based damage detection of a damaged steel truss bridge. Engineering Structures, 2016, 122: 156173.

[46]Dyke S J, Bernal D, Beck J, Ventura C. Experimental phase II of the structural health monitoring benchmark problem. Proceedings of the 16th ASCE engineering mechanics conference. 2003. 